\title{
Transcription of the putative tumor suppressor gene HCCS1 requires binding of ETS-2 to its consensus near the transcription start site
}

\author{
Jing De Zhu ${ }^{1,2}$, Qi Fei ${ }^{1, *}$, Peng Wang ${ }^{1, *}$, Fei Lan ${ }^{1, *}$, Da Qin Mao ${ }^{1, *}$, Hong Yu Zhang ${ }^{1}$, Xue Biao Yao ${ }^{3}$ \\ ${ }^{I}$ Laboratory of Cancer Epigenetics and Gene Therapy, The State-Key Laboratory for Oncogenes and Related Genes, Shanghai Cancer \\ Institute, Shanghai Jiaotong University, LN 2200/25, Xietu Road, Shanghai 200032, China; ${ }^{2}$ School of Life Sciences, Zhejiang Sci- \\ ence and Technology University, Xiasha University District, Hangzhou, Zhejiang 310018, China; ${ }^{3}$ Laboratory of Cellular Dynamics, \\ University of Science and Technology of China, Hefei 230027, China
}

The hepatocellular carcinoma suppressor 1 (HCCS1) gene was identified by both positional cloning from a predominant region of loss of heterozygosity $(17 \mathrm{p} 13.3)$ in liver cancer and by functional screening for genes affecting cell proliferation in large-scale transfection assays. Its overexpression results in inhibition of cell proliferation in cell culture and tumor growth in nude mice. To understand its transcription regulation, the promoter architecture has been dissected in detail. The major start of transcription was mapped by primer extension to a $\mathrm{C}$ residue, 177 nucleotides upstream of the ATG codon. By assessing the promoter activity of a set of linker-scanning mutants of the minimal promoter $(-60$ to +148 region) in a transient transfection assay, we found that the +1 to +40 region is critical to HCCS1 gene transcription, containing binding sites for transcription factors NF- $\mathrm{KB}(-21$ to +7 and +40 to +26$), \mathrm{p} 53(+29$ to +9$)$ and ETS $(+4$ to +20 and +23 to +39). Biochemical and molecular analyses revealed that the ETS transcription factors ETS-2 and Elf- 1 bind to the two ETS sites in situ and contribute significantly to the transcriptionally active state of the HCCS1 gene, while NF-кB, p53 and two other members of the ETS family (ETS-1 and NERF2) appear to play little role. Our observations provide insight into the mechanistic aspects of HCCS1 transcription regulation.

Cell Research advance online publication 5 Sep 2006; doi: 10.1038/sj.cr.7310092

Keywords: HCCS1 gene, transcription regulation, ETS, p53, NF-кB

\section{Introduction}

Hepatocellular carcinoma (HCC) presents a major health threat to the people of the world, particularly in mainland China, where over $50 \%$ of the worlds' total incidence and mortality from HCC occurs [1]. A better understanding of the genetic and epigenetic aberrations associated with $\mathrm{HCC}$ is expected to lead to a significant improvement in the clinical management of this malignancy [2]. The hepatocellular carcinoma suppressor 1 (HCCS1) gene (AF246287) was identified by both positional cloning from a predominant

\footnotetext{
*These four authors contributed equally to this work.

Correspondence: Jing De Zhu

Tel: +86-21-64224285

E-mail: zhujingde@yahoo.com

Received 13 Jun 2006; revised 31 Jul 2006; accepted 4 Aug 2006
}

loss of heterozygosity region $(17 \mathrm{p} 13.3)$ in liver cancer [3] and by functional screening for genes affecting cell proliferation in large-scale transfection assays $[3,4]$. Its overexpression results in inhibition of cell proliferation in cell culture and tumor growth in nude mice [3]. Mutations affecting the integrity of the HCCS1 protein have been found in liver cancer tissues $[3,5]$; however, the molecular mechanisms underlying the transcriptional regulation of the HCCS1 gene remain unknown.

The crucial and definable event for transcription regulation is concerned with sequence-specific DNA-protein interactions in the context of chromatin, the real state of the genome [6-8], the details of which are therefore "musthave" information. The upstream signaling pathways that govern the transcriptional state of any gene involved in functionally important responses should also be defined. Hence, we have carried out a detailed analysis of the crucial DNA-protein interactions involved in the transcriptionally active state of the HCCS1 gene, and concluded that 
the in situ binding of ETS-2 and Elf-1 to their consensus sequences within the +1 to +40 region is functionally essential. We have also investigated whether NF- $\kappa B$ and/or the p53-mediated pathways are involved in the control of HCCS1 transcription. Our results provide new insights into the mechanisms of $\mathrm{HCCS} 1$ transcriptional regulation.

\section{Materials and Methods}

Cells, cell culture and transient transfection/reporter assays The cell lines used were three HCC cell lines, SMMC7721 (Cell Bank No. TCHu68, China), BEL740 (Cell Bank No. TCHu13, China) and Hep3B (ATCC No. HB 8064); an immobilized hepatocyte cell line, LO2 (Cell Bank No. GNHu6, China); an osteosarcoma cell line, U2OS (ATCC No. HTB-96); a breast cancer cell line, MCF7 (ATCC No. HTB-22); an erythrocytic leukemia cell line, K562 (ATCC No. CCL-243); a cervical cancer cell line, C33A (ATCC No. HTB-31); two ovarian cancer cell lines, SKOV3 (ATCC No. HTB-77) and PMH08910; a bladder cancer cell line, 5637 (ATCC No. HTB-9); and a homemade immobilized fibroblast cell line. All the cell lines were cultured in a healthy state at $37^{\circ} \mathrm{C}$ in Dulbecco's modified Eagle's medium containing $10 \%$ fetal calf serum. The transient transfection and reporter assays were carried out using Lipofectamine (Invitrogen, Carlsbad, CA, USA). We used target constructs based on pGL3-basic (5 ng; based on firefly luciferase gene) and $4 \mathrm{ng}$ of CMV renilla luciferase construct in duplicate wells of 96-well plates. Firefly and renilla luciferase activities in cell lysates were measured with a single-tube assay system (Dual-luciferase reporter assay system, Promega, Madison, WI, USA) in a Lumat luminometer (LB 9506). The promoter potency of the tested fragments is presented as the mean (and standard deviation, SD) of the ratio of the firefly luciferase and the renilla luciferase activities (relative luciferase activity: RLA, units). All the experiments were carried out three times, and the results from one representative experiment are shown. Before analysis, the SMMC7721 cells were treated with TNF- $\alpha(10 \mathrm{ng} / \mathrm{ml})$ or doxorubicin (Dox, $\mu \mathrm{g} / \mathrm{ml}$ ) for $24 \mathrm{~h}$ to activate the NF- $\mathrm{KB}$ and $\mathrm{p} 53$ pathways, respectively.

\section{$R N A$ preparation and expression profiling by a semi-quan- titative PCR}

Total RNA was prepared from cultured cells using Trizol reagent according to the manufacturer's instruction (Invitrogen) and then reverse transcribed using oligo(dT) as primer and Superscript II ${ }^{\mathrm{TM}}$ RNase H-Reverse Transcriptase (Invitrogen). Semi-quantitative PCR was carried out with primer pairs for the $\beta$-actin internal control (5'-AAG TAC TCC GTG TGG ATC GG-3' and 5'-TCA AGT TGG GGG ACA AAA AG-3' (the expected PCR product was $617 \mathrm{bp}$; XM 037235)) and the HCCS1 gene (AF246287, 5'-AGG GCA GAA CTT GCC AAG-3' and 5'-ACA CTT GGAAAC AAT GCC-3'). The PCR was carried out as follows: $94{ }^{\circ} \mathrm{C}$ for $2 \mathrm{~min}$, followed by $25-30$ cycles of $94{ }^{\circ} \mathrm{C}$ for $15 \mathrm{~s}, 60{ }^{\circ} \mathrm{C}$ for $15 \mathrm{~s}$ and $72{ }^{\circ} \mathrm{C}$ for $30 \mathrm{~s}$. The PCR products were separated on a $1.5 \%$ agarose gel, stained with ethidium bromide bands and visualized under UV illumination.

\section{Mapping of the transcription start site by primer extension analysis [9] \\ The HCCS1 gene-specific antisense oligonucleotides PE1 (5'- CTC CAG TTC CTC CTC CTC CAT CAT TCC GCC AC-3', -8 to}

+24 bp) and PE2 (5'-ACC CAG GCC CCA GCA CAG CAA CTC CCT CG-3', -88 to $-60 \mathrm{bp}$ ) were end-labeled with $\left[\gamma^{3}{ }^{32} \mathrm{P}\right]$ ATP (about $5000 \mathrm{Ci} / \mathrm{mmol})$ using T4 polynucleotide kinase. Labeled primer $(50$ fmol) was annealed to $10 \mu \mathrm{g}$ RNA in $10 \mu \mathrm{l}$ of hybridization buffer (10 mM Tris- $\mathrm{HCl}$, pH 6.8, $1 \mathrm{mM}$ EDTA, $250 \mathrm{mM} \mathrm{KCl}$ ) at $65^{\circ} \mathrm{C}$ for a minimum of $2 \mathrm{~h}$. Primers were extended with 50 units of Superscript II RNase H-Reverse Transcriptase in a solution containing $250 \mathrm{mM}$ Tris- $\mathrm{HCl}, \mathrm{pH} 8.3,25 \mathrm{mM} \mathrm{MgCl}, 50 \mathrm{mM}$ dithiothreitol, 1 $\mathrm{mM}$ dNTPs and 10 units of RNase inhibitor, for $1 \mathrm{~h}$ at $42{ }^{\circ} \mathrm{C}$. The extended products were extracted with chloroform, precipitated with ethanol and analyzed by electrophoresis on 5\% polyacrylamide-urea gels. The size of the extended products was determined by referring to the sequencing ladders generated with the equivalently labeled primers (Amersham, UK).

\section{Construction of reporter constructs and linker-scanner mu-} tants of the minimal promoter

A 1428 bp genomic fragment $(-1290$ to +148$)$ of the HCCS1 promoter region was obtained by PCR with a primer pair N1 (5'GCg gta ccG gaa ttc TGT ATA TTT TTT AGC ATT CC-3') and N2 (5'-CTT ctc gag GCC GCG AGC CCA ACT CAG-3'), followed by $K p n \mathrm{I}$ and $X h o \mathrm{I}$ digestion before cloning into the $\mathrm{KpnI}$ and $\mathrm{XhoI}$ sites of the pGL3-basic firefly luciferase reporter vector $(-1290$ to +148$)$. The 5 ' deletion mutants of this fragment were created by digesting the -1290 to +148 fragment with KpnI and BstXI (-740), PstI (-444), PvuII (-337), AvaI (-282) and SmaI (-60), respectively, followed by filling-in, ligation and cloning to create the deletion mutants -740 to $+148,-444$ to $+148,-337$ to $+148,-282$ to +148 and -60 to +148 . The 3 ' deletion mutants -1290 to +70 and -1290 to +10 were created by PCR with primer N1 with primers N3 (5'-CTT ctc gag CGG GAC CGG GGA-3') or N4 (5'-CTT ctc gag CCC GGC TCC GTC AGC CGC-3'), respectively, followed by digestion with $K p n I$ and XhoI and cloning into the pGL3-basic vector.

The linker-scanner mutants were made in the minimal promoter (ES, -60 to +148) using a two-round PCR protocol (both the protocol and the sequence of the oligonucleotides will be supplied under request) in which a 15 -nucleotide sequence was sequentially replaced with the sequence 5'-GGAATT CCT CTA GAG-3'. The mutants were mut-1 (-60 to -46$)$, mut-2 ( -45 to -31$)$, mut-3 ( -30 to -16$)$, mut-4 $(-15$ to -1$)$, mut-5 $(+1$ to +15$)$, mut-6 $(+16$ to +30$)$, mut-7 $(+31$ to $+45)$, mut-8 $(+36$ to +50$)$, mut-9 $(+51$ to +65$)$, mut $-10(+66$ to +80$)$, mut-11 $(+81$ to +95$)$, mut-12 (+96 to +110$)$, mut-13 $(+111$ to +125$)$ and mut-14 $(+126$ to +140$)$. Linker-scanner mutants of the +1 to +30 region of ES were also made, each with six nucleotides sequentially replaced with 5'-CTAGAC-3': $\mathrm{m} 1(+1$ to +6$), \mathrm{m} 2(+7$ to +12$), \mathrm{m} 3$ $(+13$ to +18$), \mathrm{m} 4(+19$ to +24$)$ and $\mathrm{m} 5(+25$ to +30$)$. In addition, the following three mutants were created: mut $-56(+1$ to +30$), \mathrm{m} 6(+11$ to +16 replaced by $5^{\prime}-$ TTTTTT- 3 ') and $\mathrm{m} 56(+11$ to +16 replaced by 5'-TTTTTT-3' and +25 to +30 replaced by 5'-CTAGAC-3').

A human Survivin promoter $(-216$ to +123$)$ construct based on pGL3-basic was made as a promoter control amenable to the wild-type (WT) p53-mediated repression [10]. The GCCC(GGACTTGCCT) sequence was placed upstream of the minimal promoter of the HSV thymidine kinase promoter $(-109$ to +52$)$ and was used as the control for the p53-responsive promoter [11]. An NF- $\kappa B$-responsive promoter was made by inserting a trimmer of its consensus sequence at the BamHI site of the pGL3-promoter reporter construct. A pGL3promoter-based reporter with a trimmer of the +1 to +40 sequence of the HCCS1 gene was also made. 
The pCI mammalian expression vector-based constructs for the ETS-1, ETS-2, NERF2 and Elf-1 genes were provided by $\mathrm{H} \mathrm{Ji}$ of Harvard University [39]. Both Rc/CMV-p65 and Rc/CMV-p50 were provided by $\mathrm{N}$ Rice of the National Cancer Institute (Frederick, MD, USA).

Electrophoresis mobility shift assay (EMSA) and antibody mediated supershift analysis

Nuclear extracts were prepared from cultured cells by a modified Dynan's protocol [10]. The EMSA and supershift analyses of the in vitro DNA-protein interaction were carried out as described previously [12]. The oligonucleotides used for this study are shown in the relevant figures. Protein extract $(5 \mu \mathrm{g})$ was incubated on ice for 20 min with $10 \mathrm{fmol}$ of ${ }^{32} \mathrm{P}$-end-labeled oligonucleotides in $20 \mu \mathrm{l}$ of a solution containing $1 \mu \mathrm{g}$ of poly-(dI:dC) (Pharmacia), $12.5 \mathrm{mM}$ HEPES, pH 7.9, $6.25 \mathrm{mM} \mathrm{MgCl}_{2}, 50 \mathrm{mM} \mathrm{KCl}$ and $10 \%$ glycerol. The DNA-protein complexes were analyzed in a cold room (about $7{ }^{\circ} \mathrm{C}$ ) by electrophoresis on nondenaturing $4 \%$ polyacrylamide gels with $0.5 \times \mathrm{TBE}$ as the running buffer $(1 \times \mathrm{TBE}: 89 \mathrm{mM}$ Tris- $\mathrm{HCl}, 89$ $\mathrm{mM}$ boric acid, 8 mM EDTA, pH 8.0). A 20-100-fold molar excess
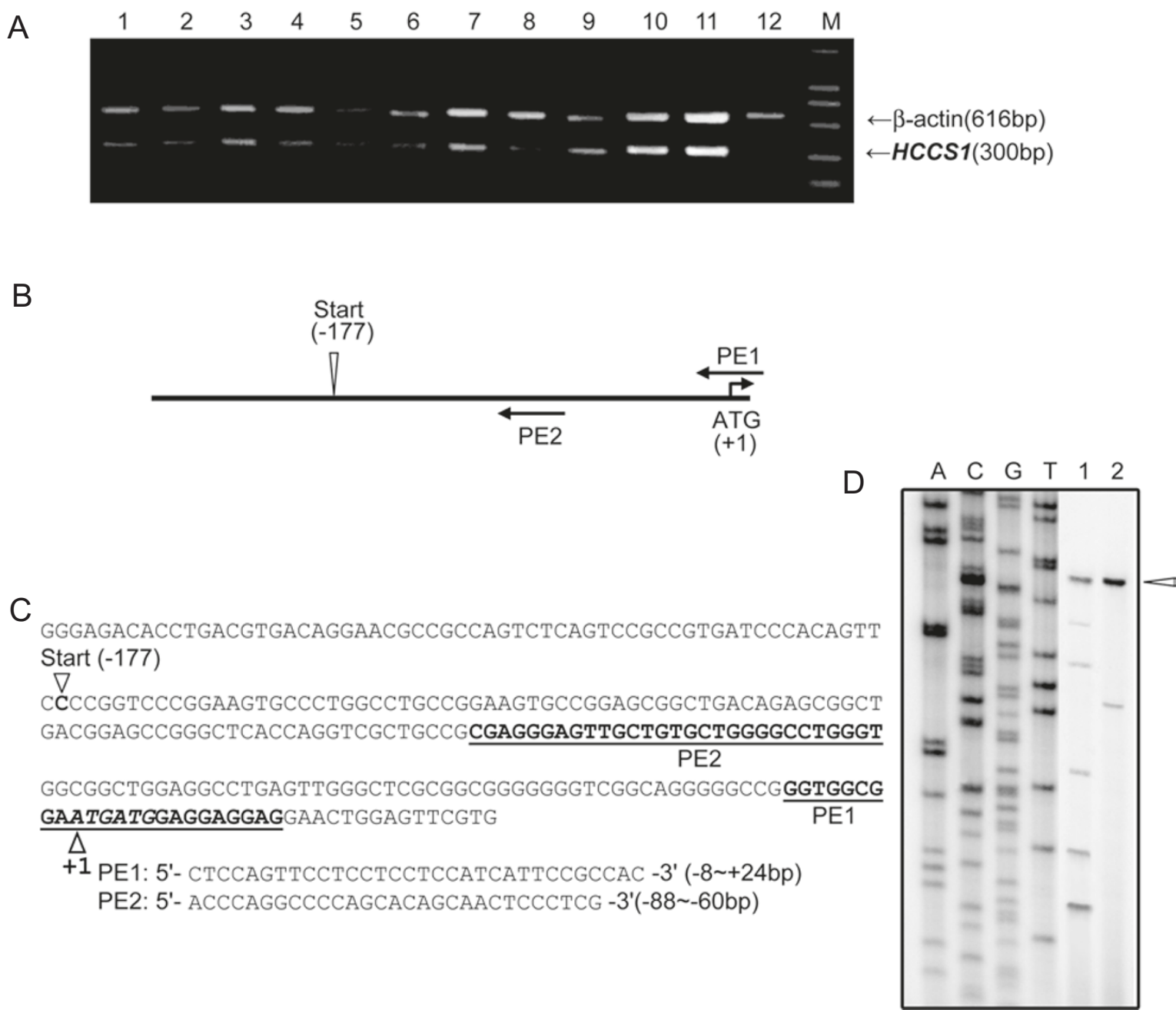

Figure 1 Expression status of the HCCS1 gene in cell lines and mapping of its major transcription start site. (A) RT-PCR reactions were performed with pairs of primers for HCCS1 (300 bp product) and $\beta$-actin ( $616 \mathrm{bp}$ product) in the same tube. Lane 1, an immobilized fibroblast cell lines; lane 2, LO2; lane 3, SMMC7721; lane 4, BEL7402; lane 5, Hep3B; lane 6, U2OS; lane 7, MCF7; lane 8, K526; lane 9, C33A; lane 10, SKOV3; lane 11, PM-HO8910; lane 12, 5637 cells lines; and M, the DL2000 size markers. (B and C) Primer extension was carried out with $10 \mu \mathrm{g}$ of total RNA from LO2 (lane 1) or SMMC7721 (lane 2) and 0.5 pM 5' ${ }^{32} \mathrm{P}-1 \mathrm{abeled}$ primer PE2 (as indicated in (B) and (C)). The major start of transcription was mapped to residue C, about 177 residues upstream of the A residue of the first ATG codon. (D) The sequence ladders of primer PE2 were electrophoresed in parallel (lanes A, G, C and T on the sense strand sequence) with the primer extended products from the LO2 (lane 1) and SMMC7721 cells (lane 2). The longest extended product, demarcating the start of transcription, is marked with an open triangle (B-D). 
of the double-stranded oligonucleotides of the competitors was included in the binding reaction for the specific competition analyses. For the supershift experiments, $2 \mu \mathrm{g}$ of antibodies against ETS-1 (sc-22802), ETS-2 (sc-22803), Elf-1 (sc-631), p50 (sc-7178), p65 (sc-7151) and p53 (sc-2579) (Santa Cruz Biotechnology, Santa Cruz, CA, USA) were preincubated with the protein extracts for 5 min before the EMSA reaction. After electrophoresis, the gels were dried onto DEAE paper (Whatman DE81) for autoradiography or phosphoimager analysis.

Chromatin immunoprecipitation analysis for in situ proteinDNA interactions in the +1 to +40 region

Immunoprecipitation of the cross-linked chromatin was carried out according to the manufacturer's instructions (Active-Motif, Carlsbad, CA, USA). SMMC7721 cells in log phase were crosslinked with $1 \%$ formaldehyde for $10 \mathrm{~min}$ at $37^{\circ} \mathrm{C}$. Free aldehyde was quenched by the addition of glycine to $0.125 \mathrm{M}$ for $10 \mathrm{~min}$ at room temperature. Cells were washed twice with cold PBS, scraped free, collected by centrifugation and fragmented by sonication. The sonicated cross-linked chromatin from $10^{6}$ cells was immunoprecipitated with $2 \mu \mathrm{g}$ of antibodies against ETS-1, ETS-2, Elf-1, p50, RNA polymerase II or nonspecific IgG control (in Chip-IT kit, 53001-53007, Active Motif, USA). One-fifth of the recovered DNA from each experiment was amplified by PCR with Hot start Taq polymerase (Toyobo, Japan) and the primer pair of ChIPUP 5'-GAC ACC TGA CGT GAC AGG AA-3' and ChIPDOWN 5'-GTC AGC CGC TCT GTC AGC-3' with the following conditions: $94{ }^{\circ} \mathrm{C}$ for 3 min, 36 cycles of $94{ }^{\circ} \mathrm{C}$ for $15 \mathrm{~s}, 59^{\circ} \mathrm{C}$ for $30 \mathrm{~s}$ and $72{ }^{\circ} \mathrm{C}$ for $30 \mathrm{~s}$, and then a further $72{ }^{\circ} \mathrm{C}$ for $5 \mathrm{~min}$. The target fragment spans from residues -56 to +61 of the $H C C S 1$ gene ( $117 \mathrm{bp}$ in length). The input control was given by one eight-hundredth of the starting sonicated chromatin from $10^{6}$ cells.

\section{Results}

The HCCS1 gene is ubiquitously expressed in tumor cell lines of various tissue origins

To select suitable cell lines for the promoter analysis, the mRNA level of the HCCS1 gene was assessed by a semiquantitative PCR assay in which both the internal control (the $\beta$-actin) and HCCS1 gene transcripts were analyzed simultaneously in the same tube. All the tested cell lines expressed HCCS1 mRNA abundantly, at a level similar to that of $\beta$-actin (Figure 1A). The cell lines studied included an immobilized fibroblast cell line (homemade); a hepatocyte cell line, LO2; three HCC cell lines, SMMC7721, BEL-7402 and Hep3B; an osteosarcoma cell line, U2OS; a breast cancer cell line, MCF7; an erythrocytic leukemia cell line, K562; a cervical cancer cell line, C33A; a bladder cancer cell line, 5637; and two ovarian cancer cell lines, SKOV3 and PM-HO8910. The SMMC7721 and LO2 cell lines were chosen for subsequent analysis.

The start site of transcription is one of the key cis-elements for the control of gene transcription. The primer extension analysis was carried out using total RNA from LO2 and SMMC7721 cells to map the major start site of transcription. The first attempt with PE1 (+24 to -8$)$ resulted in extended products greater than 170 nucleotides in length from both cell lines (not shown). The primer extension was then followed with an upstream primer, PE2 ( -60 to -88 ), where +1 was defined as the A residue of the ATG of the translation initiation codon (Figure 1B). Using the sequencing ladders by primer PE2 as references, the major transcription start site was mapped to a $\mathrm{C}$ residue, 177 nucleotides upstream of the translation initiation codon. In the remaining sections, all the $c i s$-information is defined by taking this residue, as the major start of transcription, as position +1 , rather than the A residue of the first ATG codon.

The minimal promoter of the HCCS1 gene spans from -60 to +148 and contains two ETS consensus sites within the +1 to +40 region of functional importance

A firefly luciferase-based reporter construct (pGL3-basic) driven by an upstream 1438 bp DNA fragment $(-1290$ to +148 ) of the HCCS1 gene delivered a level of promoter potency similar to the pGL3-control in a transient-transfection assay in the SMMC7721 HCC cell line, which expresses a high level of the HCCS1 transcript (Figure $2 \mathrm{~A}$ ). Such potent promoter activity was also found with all the 5 ' end deletion mutants $-740,-444,-337,-282$ and -60 to +148 , indicating that the 5 ' boundary of the minimal promoter of $H C C S 1$ was no further than -60 . As the $3^{\prime}$ end deletion mutant -1290 to -11 was transcriptionally inactive, and the mutant -1290 to +70 exhibited a moderate but significant reduction of promoter activity by about $20 \%$ (Figure 2A); the minimal promoter of the HCCS1 gene is likely in the -60 to +148 region.

With the assistance of $c i s$-element identification software (http://transfac.gbf.de/TRANSFAC), 11 candidates with matrix similarity greater than 9.44 , plus the $\mathrm{p} 53$ consensus site, were found unevenly distributed in the -60 to +148 region. Four cis-elements are located in the -60 to -46 region, five in the +1 to +40 region, one in the +88 to +92 region and two in the +97 to +125 region (Figure 2A). The most direct experimental approach is to determine the highest negative impact of mutations targeted to each of the bioinformatically predicted cis-elements on the promoter activity in transient transfection assays. However, this approach has two shortcomings: first, the cis-element entries in the current database vary drastically in quality [13]; second, cis-elements not characterized previously are excluded from further study. Therefore, an alternative approach was taken. 14 replacement mutants were made, each of which targeted a 15-nucleotide block within the -60 to +148 region by replacing the block with 5'-GGAATT CCT CTA GAG-3' that is devoid of the known cis-elements. The negative impact of each mutant was measured. As indicated 
A



SIP(-) $\overline{I A} \bar{T} \bar{F} \bar{T} \bar{E} \bar{E}$ MESIS(-)

-60 GGGA'GACACC TGACGTGACA GGAACGCCGC CAGTCTCAGT CCGCCGTGAT CCCACAGTTC

ETS

+1 CCQGGTECCG GAAGTGCCCT. GGCCTGCCGG AAGTGCCGGAj GCGGCTGACA GAGCGGCTGA

$\underset{\text { Start }}{\mathrm{p} 53(-)}$

MUSCLE INI(-)

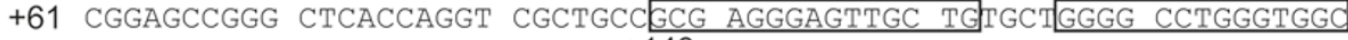
$+148$

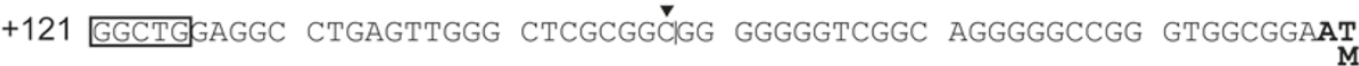

+181 GATGGAGGAGGAGGACTGGAGTTCGT +208

$\begin{array}{lllllllll}M & E & E & E & E & L & E & F & V\end{array}$

B

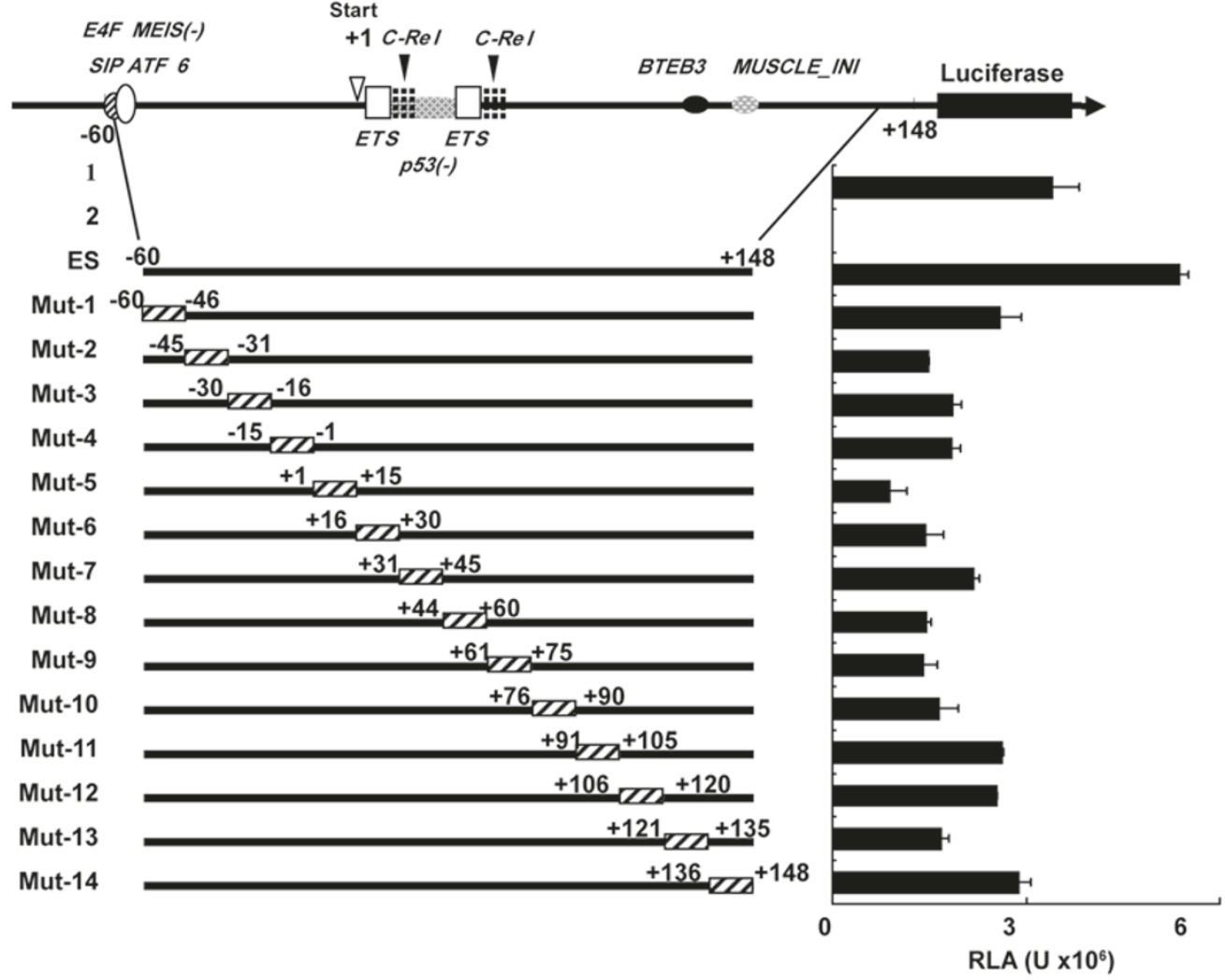

Cell Research | www.cell-research.com 
C

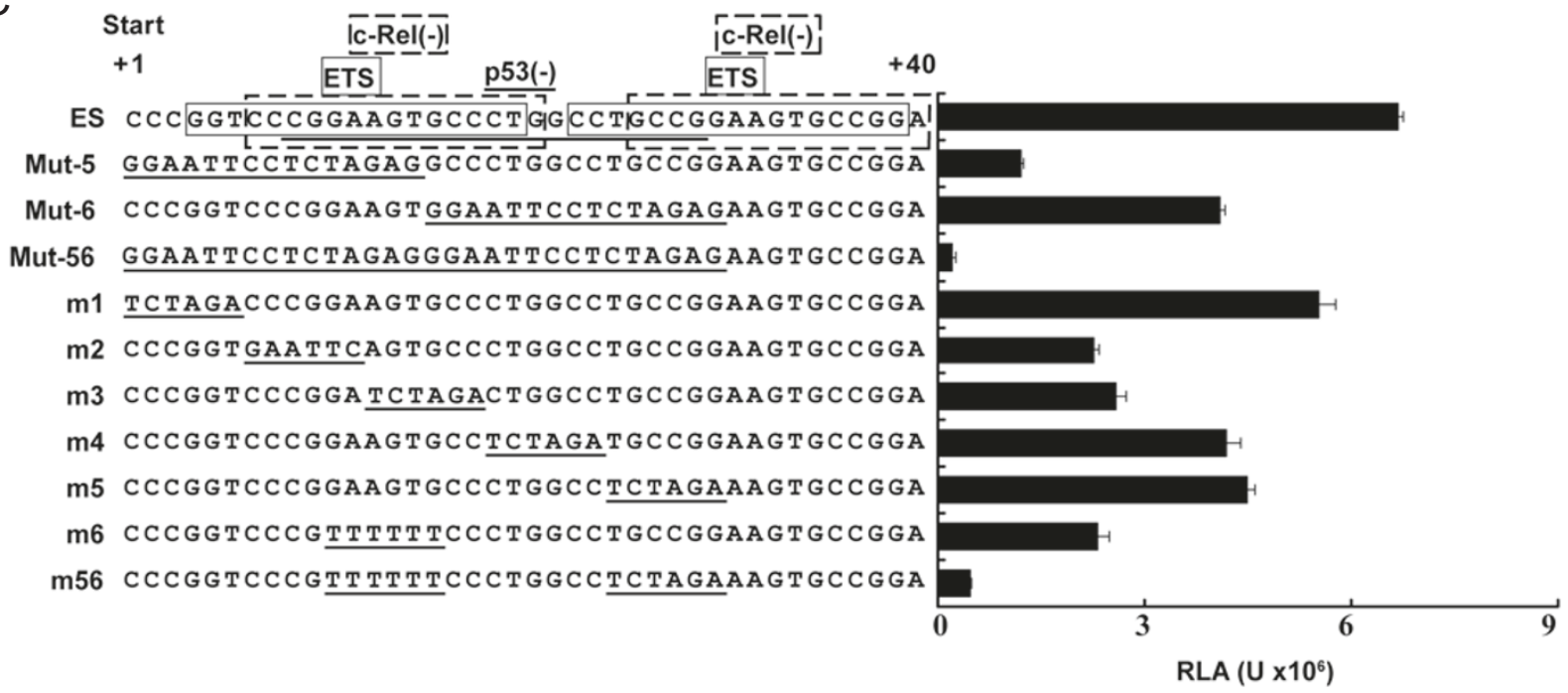

D
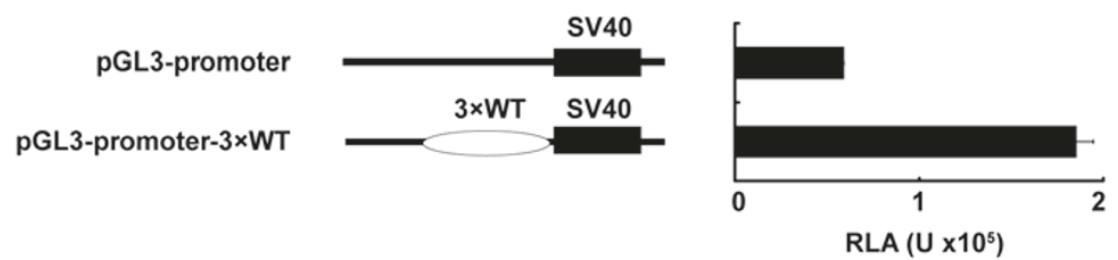

Figure 2 Minimal promoter and crucial cis-elements were identified by transient-transfection reporter analysis in SMMC7721 cells. (A) pGL3-basic reporter constructs with the upstream region $(-1290$ to +148$)$, its 5 ' deletion mutants (five) and 3' deletion mutants (two) were made and transfected into SMMC7721 cells. The relative luciferase activity (RLA plus SD, $U \times 10^{6}$ ) of each construct is plotted. The cis-elements with matrix similarity above 9.44 in the -60 to +148 region are indicated in the context of the sequence by boxing, gray shading or underlining of both the sequence and the name. (-) refers to consensus sequences in the antisense strand. The DNA sequence from the translation start $(+179)$ to +208 along with the amino-acid sequence are also shown in bold. (1) pGL3control: the firefly luciferase gene is under the control of the SV40 early promoter and enhancer. (2) pGL3-basic: a promoter-less control. (B) Architectural details of the minimal promoter (ES) and its linker-scanner mutants (mut-1 to mut-15) are presented. The promoter potency of each, represented by RLA plus SD, is plotted. (C) Sequence details of the +1 to +40 region of ES and its linker-scanner mutants, mut-5, mut-6, $\mathrm{m} 1$ to $\mathrm{m} 6$ and $\mathrm{m} 56$, are presented. The promoter potency (RLA plus SD) of each is plotted. (D) The promoter activity of pGL3-promoter $3 \times \mathrm{WT}$, in which a portion of the +1 to +40 (WT) region was placed upstream of the SV40 promoter of the pGL3 construct, was tested by transient transfection/reporter assay in SMMC7721 cells.

in Figure 2B, all the mutants lost more than $50 \%$ of ES promoter activity, indicating that sequence integrity at this level of resolution (a 15-nucleotide fragment as a unit) was required, no matter whether any known cis-elements were affected. The strongest effect was with the mutation at +1 to +15 (mut-5: $\Delta+1$ to +15 ), as much as $80 \%$ ES activity lost. The adjacent mutants, mut-4 $(\Delta-15$ to -1$)$ and mut-6 $(\Delta+16$ to +30$)$, lost $60 \%$ and $70 \%$ of ES activity, respectively. We further tested the replacement mutants with a 30-nucleotide sequence replaced, giving mutants mut-45 $(\Delta-15$ to +15$)$ (data not shown) and mut-56 $(\Delta+1$ to +30$)$. Only mut-56 did not exhibit promoter activity (Figure 2C). Therefore, the crucial cis-elements for HCCS1 transcrip- tion exist within the +1 to +30 region. This observation is consistent with the finding that an approximately two-fold increase in promoter activity was produced by a trimmer of the +1 to +40 sequence inserted in the pGL3-promoter reporter construct (Figure 2D).

To further map the crucial cis-elements within the +1 to +30 region, a set of linear-scanning mutants was made and tested in the context of the minimal promoter (ES). Each mutant had a six-nucleotide sequence replaced with 5'-TCTAGA-3' for $\mathrm{m} 1$, and $\mathrm{m} 3$ to $\mathrm{m} 5$, with 5'-GAATTC-3' for $\mathrm{m} 2$ and with 5'-TTTTTT-3' for $\mathrm{m} 6$ (Figure 2D). Whereas $\mathrm{m} 1(\Delta+1$ to +6$), \mathrm{m} 4(\Delta+19$ to +24$)$ and $\mathrm{m} 5(\Delta+25$ to +30$)$ retained $60 \%$ of ES activity, the most drastic loss $(40 \%$ of 
A

\begin{tabular}{|c|c|c|c|c|c|}
\hline & $\begin{array}{l}\text { Candidate } \\
\text { cis-elements }\end{array}$ & $\begin{array}{l}\text { Position } \\
\text { from - to }\end{array}$ & $\begin{array}{l}\text { Core } \\
\text { sim. }\end{array}$ & $\begin{array}{l}\text { Matrix } \\
\text { sim. }\end{array}$ & Sequence \\
\hline & ETS & $+4-+20$ & 1.000 & 0.983 & ggtccCGGAagtgecct \\
\hline & c-Rel(-) & $+21-+7$ & 1.000 & 0.931 & cagggcacTTCCggg \\
\hline & p53(-) & $+29-+9$ & 0.750 & 0.683 & cggCAGGccagggcacttccg \\
\hline & ETS & $+23-+39$ & 1.000 & 0.989 & cctgccGGAAgtgccgg \\
\hline & c-Rel(-) & $+40-+26$ & 1.000 & 0.919 & tccggcacTTCCggc \\
\hline $\begin{array}{l}\text { ETS-2(Elf-1): } \\
\text { ETS-2(Elf-1): }\end{array}$ & \multicolumn{5}{|c|}{$\begin{array}{l}5^{\prime}-\text { GATCTCAAOCCGGAAGTACCGA }-3 \text { ' } \\
\text { AAGTACCGA - -3' }\end{array}$} \\
\hline $\begin{array}{l}\text { WT: } \\
\text { ETS-1(pEA3): } \\
\text { ETS-1(pEA3): }\end{array}$ & $\begin{array}{r}5^{\prime}-\mathrm{CCC} \\
5^{\prime}-\mathrm{GATCT}\end{array}$ & $\begin{array}{l}\text { GGT } C C C G G \\
\text { CGA A }\end{array}$ & $\frac{\text { AAAGTS }}{5^{\prime}-}$ & $\begin{array}{l}\text { CCCTGGC } \\
\text { CGA - 3' } \\
\text { GATCTC }\end{array}$ & 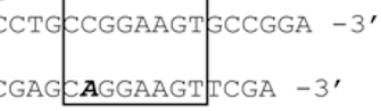 \\
\hline $\begin{array}{r}\text { p53: } \\
\text { NF-KB: }\end{array}$ & $\begin{array}{l}5^{\prime}-\text { TACAGA } \\
5^{\prime}-\text { AGTTGA }\end{array}$ & $\begin{array}{l}\text { ACATGTCTA } \\
\text { GGGGACTTT }\end{array}$ & $\begin{array}{l}\text { AAGCATC } \\
\text { TCCCAG }\end{array}$ & $\begin{array}{l}\text { GCTGGGG } \\
\text { GC }-3^{\prime}\end{array}$ & $-3^{\prime}$ \\
\hline
\end{tabular}

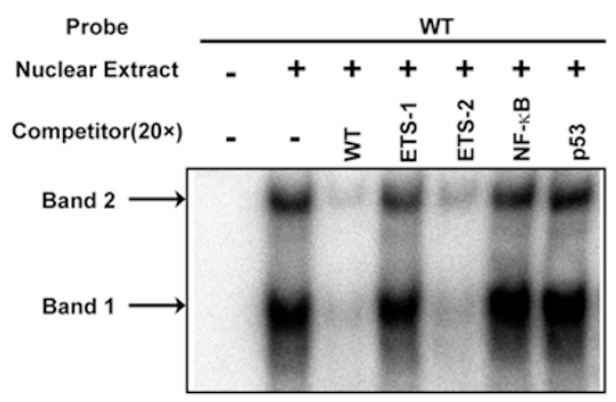

B

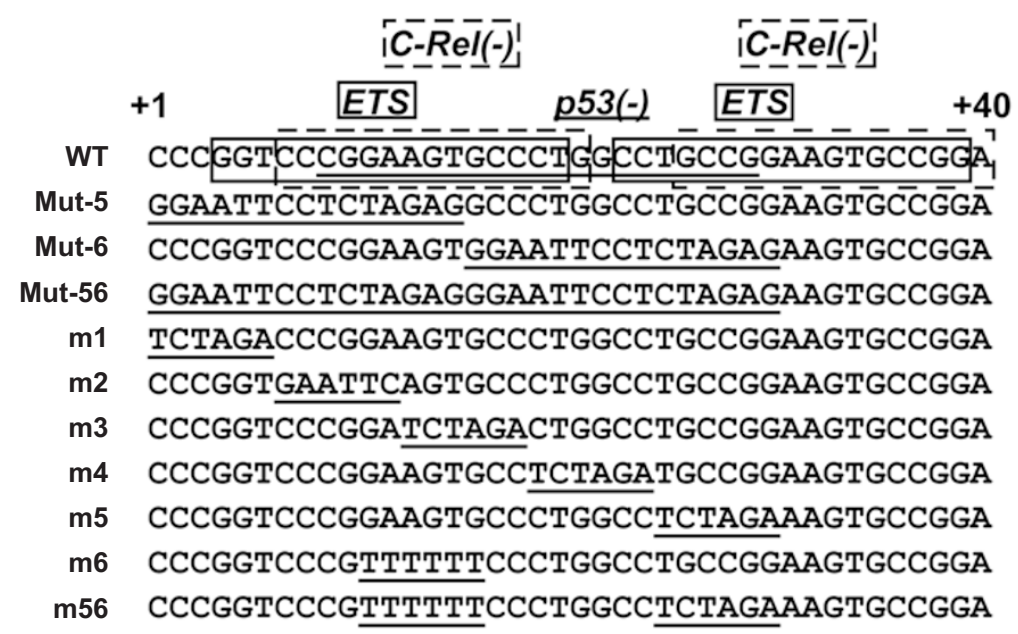

Figure 3 In vitro sequence-specific DNA-protein binding of +1 to +40 sequence (WT) and SMMC7721 nuclear proteins by EMSA. (A) The consensus sequences for ETS, c-Rel (NF-kB) and p53 binding identified by bioinformatics in the +1 to +40 region are shown with the position, the values for core similarity ( $\operatorname{sim}$.) and matrix similarity ( $\operatorname{sim}$.), and the actual sequences. ( - ) refers to the antisense orientation. The consensus sequences for ETS-1 (PEA3) and ETS-2 (Elf-1) binding are aligned with WT. The bold and italic nucleotides in the ETS-1 consensuses differ from both ETS-2 consensus sequences and the WT. The EMSA result is shown with the WT as probe. (B) Sequence alignment of the WT sequence with each of the replacement mutants. (C) EMSA results are shown with the WT as probe and with each of the replacement mutants (B) as the competitors. (D) EMSA results with m5, m6, m56 and WT as probes. (E) Supershift results with the SMMC7721 nuclear extracts and the WT sequence as probe, with the antibodies and $\mathrm{H}_{2} \mathrm{O}$ or PBS controls, as indicated at the top of the autoradiograph. The band supershifted (band 3) by anti-ETS-2 is marked with an open triangle. (F) The supershift results with the SMMC7721 nuclear extracts and the $\mathrm{m} 5$ or $\mathrm{m} 6$ sequences as probes with the antibodies, as indicated at the top of the autoradiograph. The band supershifted by anti-Elf-1 is marked with an open triangle. 
C

\begin{tabular}{|c|c|c|c|c|c|c|c|c|c|c|c|c|c|}
\hline Probe & \multicolumn{13}{|c|}{ WT } \\
\hline Nuclear Extract & - & + & + & + & + & + & + & + & + & + & + & + & + \\
\hline ompetitor(20x) & - & - & 々 & 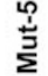 & 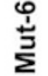 & 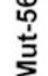 & $\bar{\xi}$ & ๕ี & $\stackrel{m}{\xi}$ & है & है & $\stackrel{\mathscr{E}}{E}$ & ఋ \\
\hline
\end{tabular}

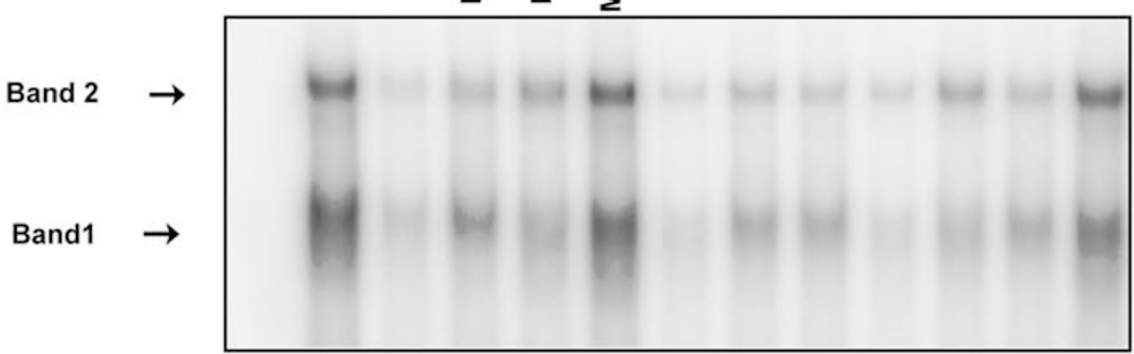

D

\begin{tabular}{|c|c|c|c|c|c|c|c|c|c|c|c|}
\hline Probe & & n5 & & & & & & & m56 & & WT \\
\hline tract & - & + & + & - & + & + & + & - & + & + & - \\
\hline $20 \times)$ & - & $\stackrel{\mathscr{E}}{\text { है }}$ & 5 & - & - & $\stackrel{\varrho}{\xi}$ & 5 & - & ڤ్ & 5 & - \\
\hline
\end{tabular}

E
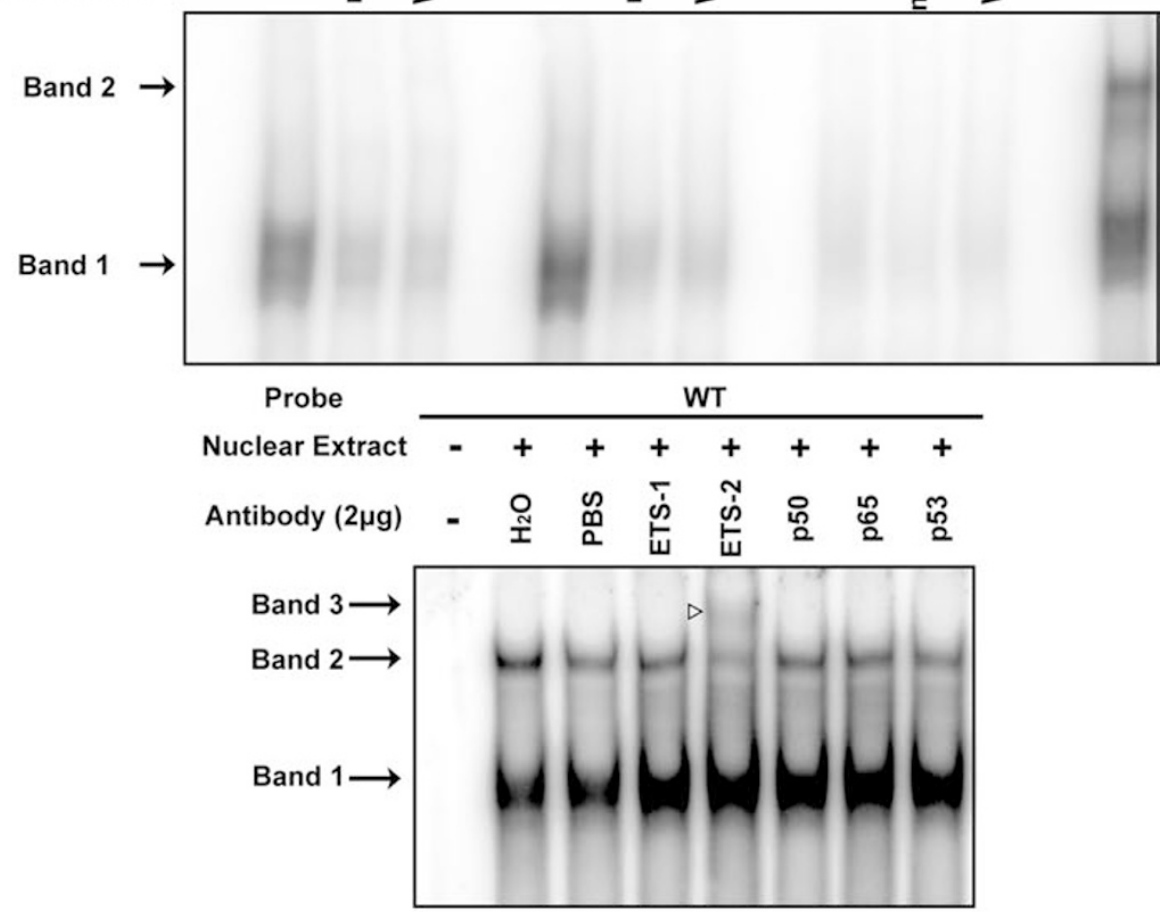

F

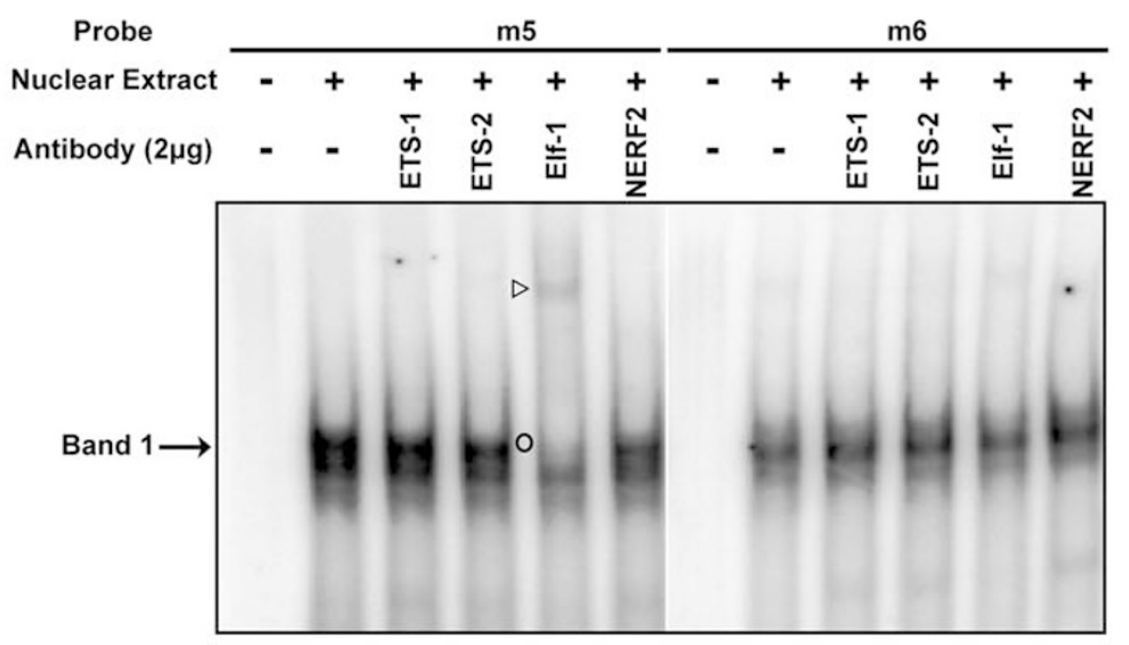


ES activity remaining) was found with $\mathrm{m} 2(\Delta+7$ to +12$)$ and $\mathrm{m} 3(\Delta+13$ to +18$)$. The +7 to +18 sequence overlapped to various extents with each of the following three types of cis-elements: (1) two ETS sites in the sense strand: 5'GGT CCC GGAAGT GCC CT-3', +4 to +20, and 5'-CCT GGC GGAAGT GCC GG-3', +23 to +39; (2) a p53 site in the antisense strand (-): 5'-CGG CAG GCC AGG GCA CTT CCG-3', +29 to +9; and (3) two c-Rel (NF-кB) sites in the antisense strand: 5'-CAG GGC ACT TCC GGG-3', +21 to +7 , and 5'-TCC GGC ACT TCC GGC-3', +40 to +26 . The two ETS sites (matrix similarity 0.983 and 0.989 ) scored significantly higher than the p53 (0.683) and NF-кB consensus sequences (0.931 and 0.919) (Figure 3A), we specifically targeted these two ETS sites. The mutant, m6, where the sequence GAAGTG at +11 to +16 (the underlined is the core ETS consensus) was replaced by $(\mathrm{T})_{6}$, displayed a $60 \%$ reduction of ES activity, as did the $\mathrm{m} 2(\Delta+7$ to +12$)$ and $\mathrm{m} 3(\Delta+13$ to +18$)$. The remaining $40 \%$ activity might be attributed to the intact ETS consensus sequence $(+23$ to +39 ) within this region. Indeed, the two mutants where both ETS sites were replaced ( $\mathrm{m} 56(\Delta+11$ to +16 and $\Delta+25$ to +30$)$ and Mut-56( $\Delta+1$ to +30$))$ retained no more than $10 \%$ of ES activity (Figure 2D).

Sequence-specific binding of both ETS-2 and Elf-1 to the ETS consensus sequences within the +1 to +40 region was observed in SMMC7721 nuclear extracts

To identify the transcription factors involved in HCCS1 transcription, we carried out in vitro analyses by EMSA for sequence-specific protein-DNA interaction between SMMC7721 nuclear proteins and the double-stranded probe comprising +1 to +40 sequence (WT) as probe. Two shifted bands ( 1 and 2) were observed, which were largely abolished by a $20 \times$ excess of the cold WT oligonucleotide and ETS-2 (or Elf-1, another ETS transcription factor) consensus binding site oligonucleotides, but not by those for ETS-1 (or PEA3, an ETS1-related protein), NF- $\mathrm{KB}$ and p53 (Figure 3A). The key transcription factor(s) is, therefore, likely ETS-2. To correlate the promoter activity in the transient transfection assay with the in vitro sequence-specific protein-DNA binding seen in the EMSA, we compared the competing abilities of each mutated probe with the WT probe (Figure 3B and 3C). As $\mathrm{ml}(\Delta+1$ to +6$)$ had barely lost promoter activity (Figure $2 \mathrm{C}$ ), its sequences compete for binding as well as the WT sequence (Figure 3C). Both mut-56 $(\Delta+1$ to +30$)$ and $\mathrm{m} 56(\Delta+11$ to +16 and +25 to +30 ) had lost more than $90 \%$ of ES activity (Figure $2 \mathrm{C}$ ). Again, both barely competed for the WT binding (Figure $3 \mathrm{C})$. The mutants with at least one ETS site affected, +4 to +20 in mut-5, mut $6, \mathrm{~m} 2, \mathrm{~m} 3$ and $\mathrm{m} 6$, and +23 to +39 in mut- 6 and $m 5$, had a moderate level of ES activity (Figure 2C) and competing capacity (Figure 3C). EMSA analyses with $\mathrm{m} 5, \mathrm{~m} 6$ and $\mathrm{m} 56$ sequences as the probes were also carried out. A band with a mobility similar to band 1 in Figure $3 \mathrm{~B}$ was detected in the EMSA with $\mathrm{m} 5$ and $\mathrm{m} 6$ as probes (Figure 3D), indicating that it might be formed by an ETS-like protein binding to the single intact ETS site in the +1 to +40 region. Indeed, no shifted band was evident when both ETS sites were mutated in m56 (Figure 3D).

Antibody-based supershift experiments were further carried out. The antibodies against ETS-1, NERF2 [10-12] and the two components of NF- $\kappa \mathrm{B}, \mathrm{p} 50$ and p65, failed to supershift band 2; while the antibody against ETS-2 resulted in a supershifted band (band 3) (Figure 3E). Further observations strengthening the notion that ETS-2 is the key involved factor suggested from the observation that only ETS-2 consensus effectively competed for the WT binding (Figure 3B). Other experiments demonstrated that Elf-1, but none of p53, p300 and CBP antibodies supershifted band 2 (not shown). Elf-1 antibody also supershifted the band (with a similar mobility to band 1 in Figure 3B) with $\mathrm{m} 5$ probe (the +23 to +39 ETS site affected), but not $m 6$ probe (the +4 to +20 ETS site affected) (Figure 3 F). On the contrary, none of the antibodies against ETS-1, ETS-2 or NERF2 was capable of supershifting the shifted band with $\mathrm{m} 5$ or $\mathrm{m} 6$ probes. Elf-1 appears to have a more potent binding ability to the single ETS site than ETS-2, and prefers 5'-GGT CCC GGAAGT GCC CT-3' ( +4 to +20$)$ to the 5'-CCT GGC GGAAGT GCC GG-3' (+23 to +39$)$ sequences.

We further assessed the effects of the forced expressed individual transcription factors on ES promoter activity by co-transfection assay. Despite of the fact that only ETS-2 and Elf- 1 can bind to the WT sequence (Figure 3), all of the four ETS family members tested elevated ES activity in a dose-dependent manner. The effect of ETS-2 was most potent $(2 \times$ excess, 7.5 -fold; $8 \times, 10$-fold; and $16 \times, 18$-fold) and that of NERF 2 was the weakest $(2 \times$ excess, 3.5 -fold; 8 $\times, 5$-fold; and $16 \times, 6$-fold) (Figure 4A). Comparable experiments with each of the ES mutants were also performed, showing that while all the mutants with one of these two ETS sites affected responded with a moderate elevation in promoter activity, mutants with both ETS sites affected (mut-56 and m56) failed to respond to the overexpressed ETS-2 (not shown). These further strengthened the notion that ETS (ETS-2 and Elf-1) binding to both ETS sites within the +1 to +40 region is crucial to HCCS1 transcription.

We also carried out the same analysis on both p50 and p65 components of the NF- $\kappa$ B transcription factor (Figure $4 \mathrm{~A})$. Although $\mathrm{p} 65$ gave rise to an up to four-fold elevation of ES activity in a dose-dependent manner, it was much less dramatic than for ETS-2, which showed specific binding to ETS sites in vitro (Figures 3A, 3E and 4A). Similarly, the small elevation of ES activity stimulated by p50 lacked any dose dependence (Figure 4A). As SMMC7721 cell line is 
A
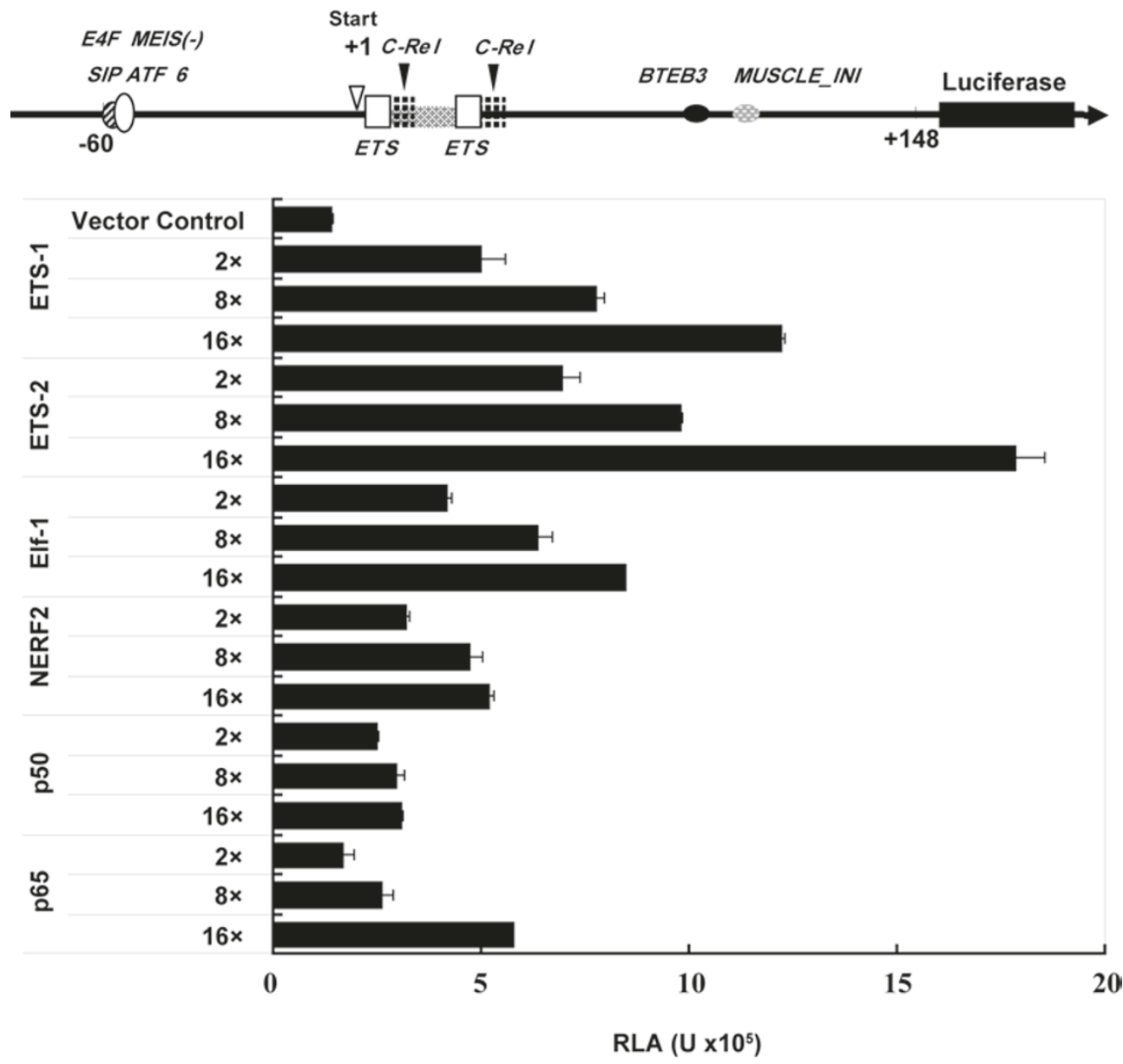

B

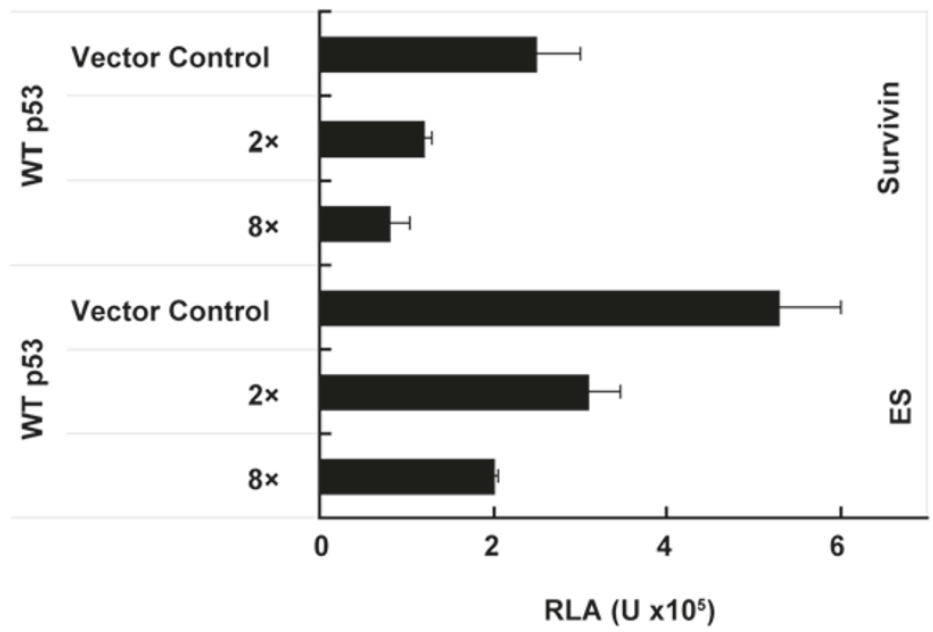

Figure 4 Effects of the overexpressed transcription factors on the activity of the ES minimal promoter in a transient transfection assay. (A) The promoter activity of ES in SMMC7721 cells was measured (RLA $\left.U \times 10^{6}\right)$ with various ratios $(2 \times, 8 \times$ and $16 \times$ excess) of the co-transfected mammalian expression constructs encoding ETS-1, ETS-2, Elf-1, NERF-2 (ETS family), and the p50 and p65 components of NF- $\mathrm{kB}$. Empty vector at 16× excess was used as the control. (B) The promoter activity of ES in 5637 (p53) cells was measured (RLA $U \times 10^{6}$ ) and shown in a plot with $2 \times$ and $8 \times$ excess of the mammalian expression vector encoding the WT p53 protein. The Survivin promote reporter construct was also analyzed. 
at the wildtype (WT) p53 status, co-transfection analysis with the WT p53 expression plasmid was executed in a p53 null cell line, 5637 . If the bioinformatics-predicted p53 consensus within the +1 to +40 region (Figure $3 \mathrm{~A}$ ) were indeed bound and transactivated by $\mathrm{p} 53$, ES activity should be elevated. As shown in Figure 4B, forced expression of WT p53 repressed the activity of the minimal promoter of both HCCS1 gene (ES) and the Survivin promoter gene ( with a well-known promoter amenable to repression by the WT p53 [13]) in a dose-dependent manner. Therefore,
A

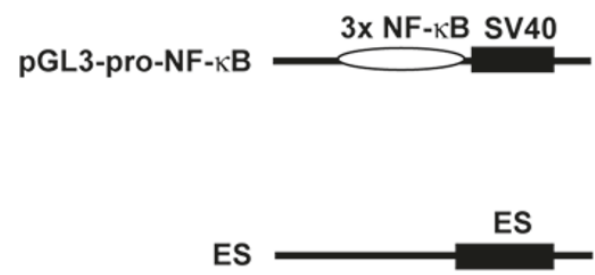

B

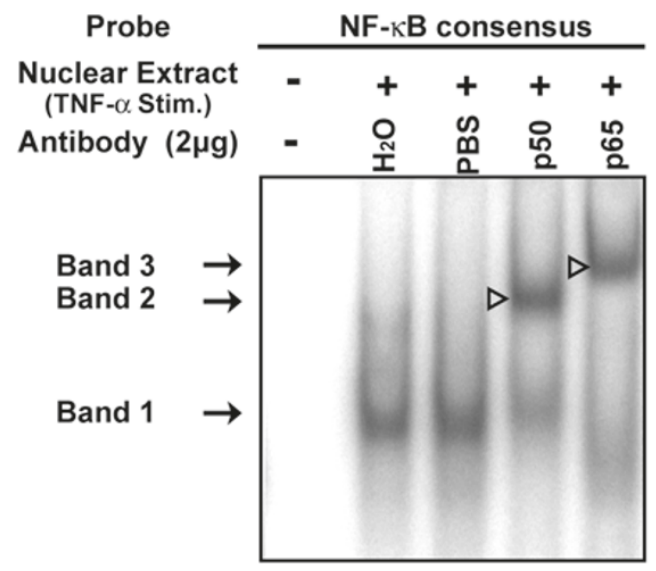

C

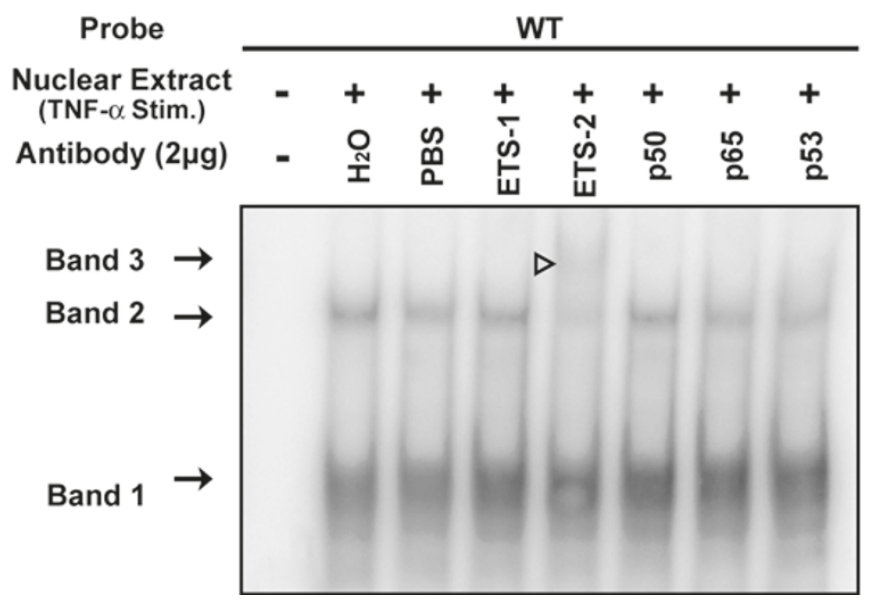


E

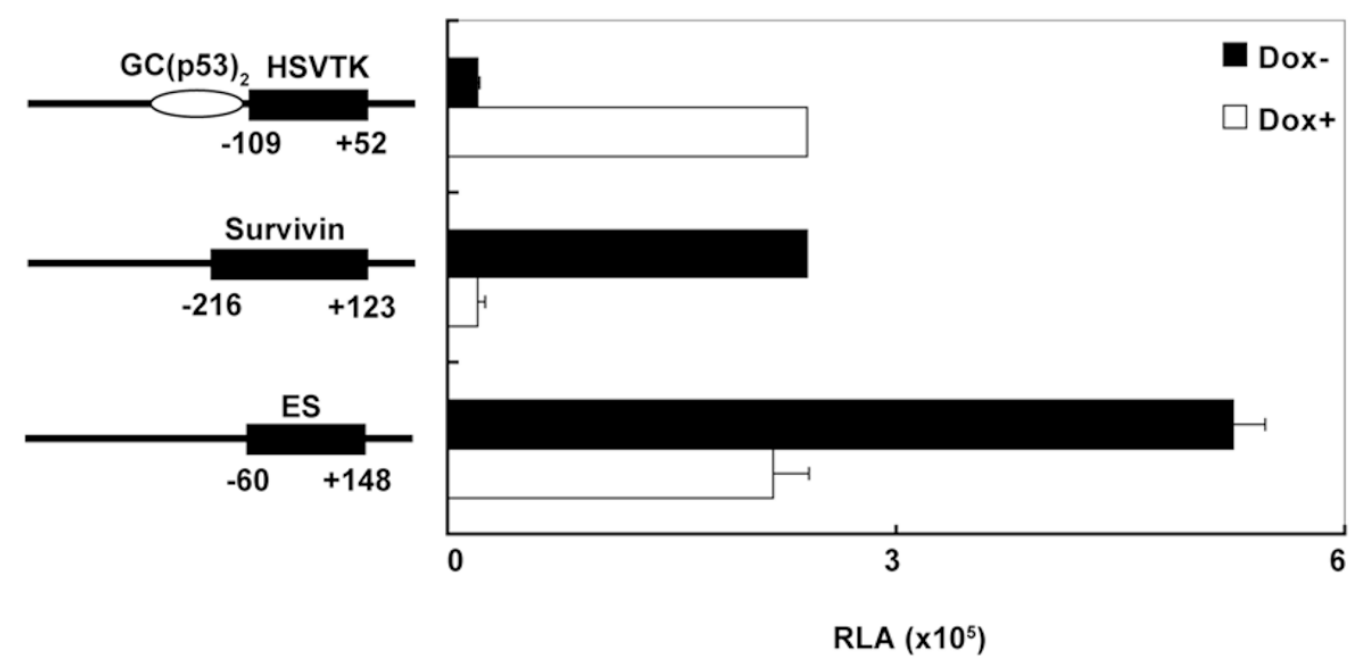

$\mathrm{F}$

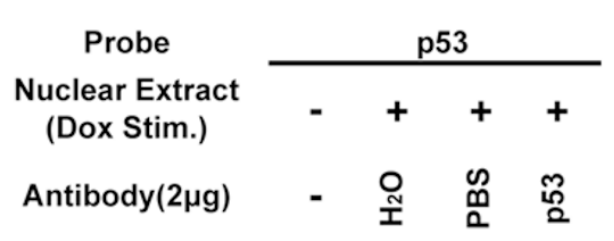

G

\begin{tabular}{|c|c|c|c|c|c|c|c|}
\hline Probe & \multicolumn{7}{|c|}{ WT } \\
\hline $\begin{array}{l}\text { Nuclear Extract } \\
\text { (Dox Stim.) }\end{array}$ & $=\quad+$ & + & + & + & + & + & + \\
\hline Antibody $(2 \mu \mathrm{g})$ & - 욤 & ભ & 它 & ஸ் & 윰 & ஜ & గొ \\
\hline
\end{tabular}
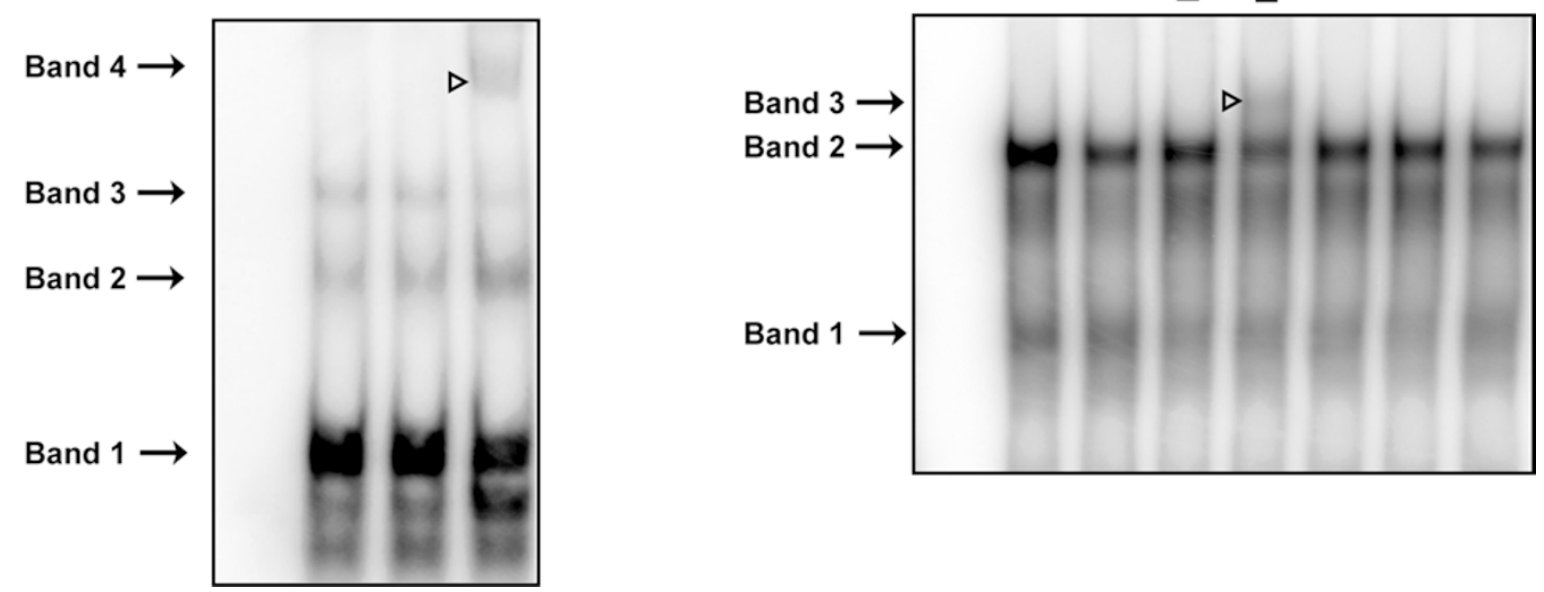

Figure 5 The activated NF- $\mathrm{BB}$ and $\mathrm{p} 53$ pathways had no effect on the transcription regulation of the HCCS1 gene. (A) The pro-

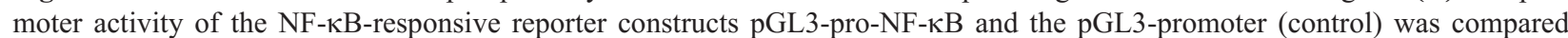
in TNF- $\alpha$-treated versus untreated SMMC7721 cells. RLA values are presented in the plot. (B) EMSA and supershift results for TNF- $\alpha$-treated SMMC7721 nuclear proteins with the NF- $\kappa$ B consensus sequence as the probe. Band 1 is DNA bound to NF- $\kappa B$ heterodimers, and bands 2 and 3 are supershifted by the anti-p50 and anti-p65 antibodies, respectively. (C) Supershift results for TNF- $\alpha$-treated SMMC7721 nuclear proteins with WT as the probe. The band supershifted by the anti-ETS-2 antibody is indicated by an open triangle. (D) p53 expression in untreated and Dox-treated SMMC7721 cells was estimated by Western analysis with the anti-p53 antibody. The control was provided by similar analysis with an anti-PCNA antibody. (E) The promoter activities of a p53responsive luciferase construct ( $\left.\mathrm{pGL} 3-\mathrm{pro}-\mathrm{GC}_{3}(\mathrm{p} 53)_{2}\right)$, the Survivin promoter and ES were measured $\left(\mathrm{RLA} U \times 10^{6}\right)$ and are shown for transfected SMMC7721 cells that were treated with or without Dox. (F) EMSA and supershift results for the nuclear proteins of the Dox-treated SMMC77211 cells with the p53 consensus sequence as the probe. Parental bands (1-3) and the supershifted band (4) are indicated. (G) Supershift results for the Dox-treated SMMC7721 nuclear proteins with WT as probe. The band shifted by the anti-ETS-2 antibody is indicated by an open triangle. 
neither the NF- $\mathrm{kB}$ nor $\mathrm{p} 53$ transcription factors have any significant binding to the bioinformatically predicted consensus sites in the +1 to +40 region both in vitro and in cell (Figures 2A and 3A). They are unlikely to contribute to the transcriptional state of the HCCS1 gene.

$N F-\kappa B$ and $p 53$ pathways do not play a role in the control of HCCS1 transcription, even in stressed cells

Both NF- $\mathrm{kB}$ and $\mathrm{p} 53$ signaling pathways are functionally dormant under the physiological conditions and are only activated when the cells experience stress. We, therefore, further examined whether stress-induced the activation of either pathway could contribute to the HCCS1 transcription. SMMC7721 cells were treated with a classic stimulus, TNF- $\alpha$, to activate the NF- $\kappa$ B pathway, and followed by analyses in the context of the regulation of HCCS1 transcription. While the promoter activity of a pGL3-based NF$\kappa B$-responsive reporter (pGL3-pro-NF- $\kappa$ B) was elevated by four-fold, ES activity was actually reduced by $20 \%$ in the TNF- $\alpha$-treated cells compared with the untreated (Figure $5 \mathrm{~A}$ ). Sequence-specific binding to the NF- $\mathrm{\kappa B}$ consensus sequence became evident in the stressed nuclear extracts, as indicated by the presence of band 1 and the supershifed bands 2 and 3 by $p 50$ and p 65 antibodies, respectively (Figure 5B). On the contrary, neither antibodies supershifted band 2 formed between the stressed nuclear proteins and the WT probe (Figure 5C). Thus, the activated NF- $\mathrm{BB}$ pathway in the stressed cells has no role in the control of HCCS1 transcription, either.

The p53 tumor suppressor protein acts as a dual functional transcription factor to regulate transcription of a spectrum of genes that have important roles in the control of cell cycle progression and stress responses. Binding to its cognate consensus sequence [14] within or near the promoter is essential for the transcriptional activation of the $\mathrm{p} 53$ 's downstream genes [15]. The $\mathrm{p} 53$ protein also effectively represses the activity of the promoters devoid of the p53 consensus sequence $[11,16,17]$. To activate the endogenous p53 pathway of SMMC7721 cells (at the WT p53 status), a well-established p53-inducing agent, Doxorubicin (DOX), was used to treat cells. Along with the increased level of the p53 protein (Figure 5D), a p53responsive promoter displayed about 10 -fold increase in activity in the stressed SMMC7721 cells (Figure 5E). In contrast, the activity of the Survivin promoter and the HCCS1 promoters (ES) was repressed by about five- and two-fold, respectively, in the stressed cells in comparison with the nontreated. This is consistent with the observation from the co-transfection experiments in p53-negative 5637 cells (Figure 4B). While the unstressed SMMC7721 nuclear protein fraction failed to produce any specific binding (not shown), the Dox-stressed SMMC7721 nuclear extract bound to the $\mathrm{p} 53$ consensus site, to create the shift of bands 1-3 in the EMSA and to band 4 by a p53 antibody in the supershift assay (Figure 5F). However, the p53 antibody did not shift band 2, between the stressed nuclear proteins and the WT probe (Figure 5C). Together, these (Figures 3-5) suggest that neither NF- $\mathrm{BB}$ - nor p53-mediated pathways affect significantly $\mathrm{HCCS} 1$ transcription in cells.

ETS-2 and Elf-1, but none of the other transcription factors tested, bind to the +1 to +40 region of the HCCS1 gene in situ

To determine whether there are in situ sequence-specific binding of ETS-2 and Elf-1 proteins, respectively, to its consensus within the +1 to +40 region, chromatin immunoprecipitation analyses were carried out in SMMC7721 cells with antibodies against ETS-2, Elf-1, ETS-1, the p50 component of NF- $\mathrm{kB}$ and polymerase II, respectively. Western blot analyses revealed that ETS-1, Elf-1, ETS-2 and p50 expressed at a compatible level in two HCCS1-expressing cell lines: SMMC7721 and C33A (Figure 6A-6D). For the ChIP analysis, the region from -61 to +56 , containing the sequence from +1 to +40 , was amplified by PCR with a pair of primers (ChIPUP and ChIPDOWN; Figure 6F). In comparison with the input control (1/800 of the cross-linked chromatin), the targeted DNA band of a similar density from one-fifth of the precipitated fraction was only detected with antibodies against ETS-2, Elf-1 and RNA polymerase II, but none of ETS-1, p50 and the IgG control. These respectively, further consolidated the conclusion that the binding of both ETS-2 and/or Elf- 1 to their consensus ( +4 to +20 and +23 to +39 ) in the crucial region for HCCSI transcription is likely to contribute to the active state of HCCS1 transcription in SMMC7721 cells.

\section{Discussion}

Aberrant transcription contributes immensely to specific patterns of gene expression and therefore to the phenotypes of tumors. Understanding the mechanistic details of the control of the transcription for any of the genes that profoundly affect the cancerous behavior of tumor cells is one of the first steps toward better understanding and management of cancer. The spatial-temporal order of transcription decision-making events involves multiple layers of controls, from the methylation state of the DNA to the higher order chromatin structure. Among these controls, sequence-specific DNA-protein interactions at regions crucial to transcription, including promoter regions, are one of the few key events that can be defined precisely both in vitro and in vivo. In responding to extracellular stimuli, cascades of biochemical events consisting of post-translational modification of proteins and their interactions and 
A

C

$\mathrm{NF}-\mathrm{KB}(\mathrm{p} 50)$

PCNA

A

A

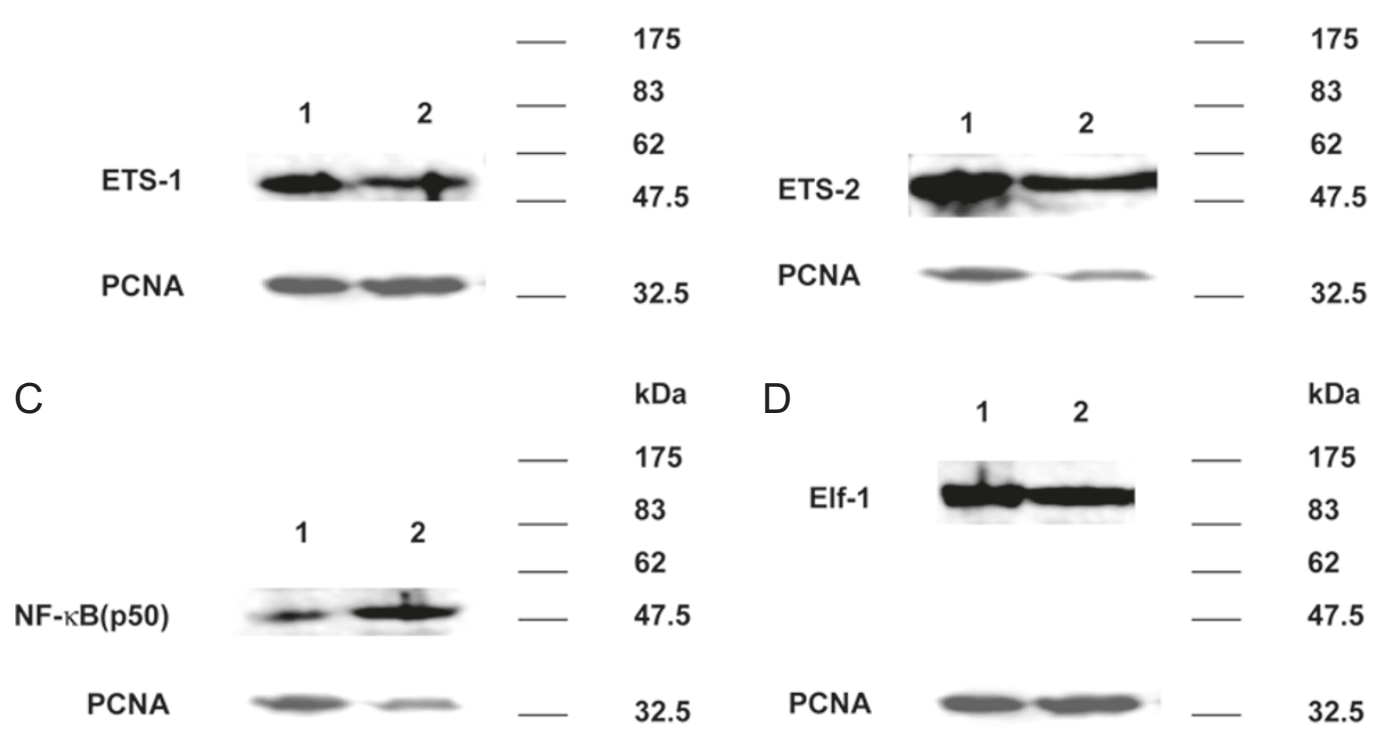

E

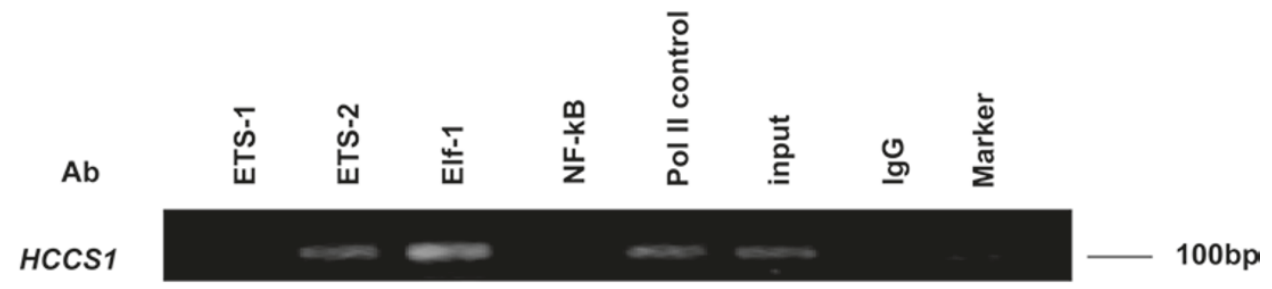

$\mathrm{F}$

ChIPUP

-60 GGGAGACACC TGACGTGACA GGAACGCCGC CAGTCTCAGT CCGCCGTGAT CCCACAGTTC

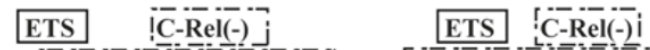

ChIPDOWN

+1 CCOGGTCCCG GAAGTGCCCT GGECTGCCGG AAGTGCCGGA GCGGCTGACA GAGCGGCTGA

$\underset{\text { Start }}{\longrightarrow}$

+61 CGGAGCCGGG CTCACCAGGT CGCTGCCGCG AGGGAGTTGC TGTGCTGGG CCTGGGTGGC

$+148$

+121 GGCTGGAGGC CTGAGTTGGG CTCGCGGĆ

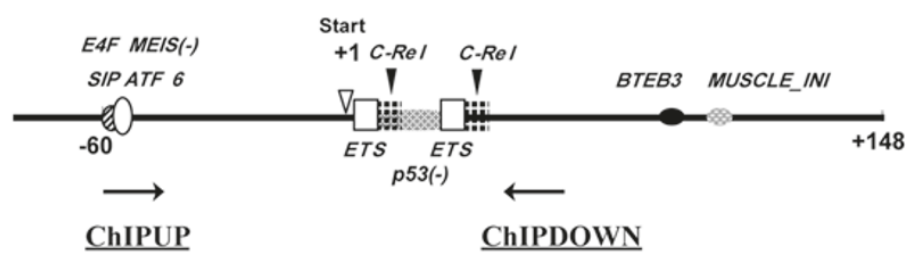

Figure 6 ETS-2 and Elf- 1 bind to the ETS consensus site in the +1 to +40 region in situ, but p50 and ETS-1 do not. (A-D) Expression levels of the transcription factors ETS-1, ETS-2, p50 and Elf-1 were estimated by Western analysis. Lane 1, SMMC7721; lane 2, C33A. The abundance of PCNA was measured as the internal control. (E) The fragment -56 to +61 was PCR amplified from onefifth of the precipitated fraction from the chromatin immunoprecipitation with the antibodies indicated at the top of the photograph, and analyzed by agarose gel electrophoresis. The control for the input was made with one eight-hundredth of the starting material for each experiment. RNA polymerase II: antibody against RNA pol II; IgG: nonspecific antibody control. The size marker DL2000 (M) was also run in parallel. (F) Schematic of the minimal promoter with detailed information from ChIP analysis. The primer pair (ChIPUP and ChIPDOWN) was as indicated. 
transportations between subcellular organelles take place in an orderly manner in cells. These ultimately alter the pattern of sequence-specific DNA-protein interactions at the regulated regions, and therefore specify the transcriptional state of the gene. Hence, knowledge of upstream signaling is also needed for a complete understanding of the transcriptional control of the gene of interest.

The HCCS1 gene was identified as a candidate tumor suppressor gene in the hepatocyte lineage $[3,4]$ and is often mutated and aberrantly expressed in liver cancers $[3,5]$. This gene is well conserved in evolution and may have a role in membrane trafficking, as suggested by the presence of a Vps53_N domain in its amino-terminus (http://www. ncbi.nlm.nih.gov/Structure/cdd/cddsrv.cgi?uid=9659) [18]. However, we remain ignorant of the exact role of the HCCS1 gene in human carcinogenesis [3, 4]. The ubiquitous pattern of overexpression in the established tumor cell lines (Figure 1A) implies that mechanisms other than control of its transcription are likely involved in the aberrant HCCS1 function in human liver cancer [3, 4]. It may be faulty in liver cancer cells because of mutations [5] and alternative splicing, as suggested by the presence of at least four spliced forms of this protein in the liver cancer cell lines (unpublished results). While disciphering the underlying mechanisms for its possible role in carcinogenesis, we have dissected the promoter architecture of the HCCS1 gene and determined the key protein-DNA interactions required for its transcriptionally active state in cells.

The direct in situ binding of ETS-2 and/or Elf-1 to their cognate consensuses at +4 to +20 and +23 to +39 determines the active state of HCCS1 transcription

The highly active state of HCCS1 transcription was suggested by the abundant level of its RNA, which matched that of the $\beta$-actin gene in all of the cell lines (Figure 1A). The promoter activity of the various 5 ' fragments, including the minimal promoter (ES, -60 to +148 ), was also as potent as that of the combination of the SV40 viral early promoter and enhancer in the pGL3-control (Figure 2A). Because conventional approaches are heavily based on bioinformatics predication [13], we comprehensively replaced each 15-nucleotide block with a sequence devoid of any known cis-elements in the context of the minimal promoter $(-60$ to +148 ) of the HCCS1 gene and assessed the impact of each mutation on promoter activity in a transient transfection assay (Figure 2B). Although cis-elements with matrix similarity greater than 9.44 are distributed unevenly in the -60 to +148 region (Figure 2A), all of the 15-nucleotide replacement mutants resulted in the reduced promoter activity (Figure 2B), irrespective of the presence of bioinformatically predicted cis-elements. The replacement mutant $\Delta+1$ to +15 suffered most, and the double mutant $\Delta+1$ to +30 lost almost its entire promoter activity (Figure 2D). This suggested that the +1 to +30 region might contain the most important cis-elements required for the HCCS1 minimal promoter activity (Figure 2B). This was consistent with the observation that a trimmer of the +1 to +30 region resulted in two-fold elevation of SV40 early promoter activity in a transient transfection assay (Figure 2C). Detailed analysis of the replacement mutants at a resolution of six-nucleotide blocks in the +1 to +30 region showed that the integrity of both sequences +7 to +12 and +25 to +30 is required for ES activity and therefore, essential to the transcriptionally active state of the HCCS1 gene (Figure 2D).

There are five $c i$-elements in the +1 to +40 region: two ETS consensus sites, one $\mathrm{p} 53$ consensus site and two c-Rel

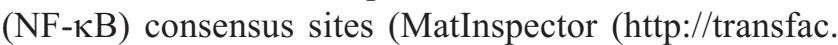
gbf.de/TRANSFAC)). Both ETS consensus sites have the highest scores with matrix similarities of 0.983 and 0.989 , while the $\mathrm{p} 53$ site is 0.683 and the NF- $\kappa B$ sites are 0.931 and 0.919 , respectively (Figure $3 \mathrm{~A}$ ). Coincidentally, the mutants with the affected GGAA/T core motif of the ETS consensus site at +7 to +12 and +25 to +30 (mut-56 and $\mathrm{m} 56$ ) lost over $90 \%$ of ES activity (Figure 2D), providing the first experimental evidence for the role of ETS-like proteins in the control of HCCS1 transcription. EMSA experiments clearly demonstrated that ETS-2 and/or Elf-1 in the nuclear protein fraction of SMMC7721 cells bound to the two ETS consensus sites, but the other tested proteins (ETS-1, p53 and NF- $\kappa$ B) did not (Figure 3A-3C). This was also supported by supershift experiments with antibodies against ETS-2, Elf-1 or ETS-1, the p50 and p 65 components of NF- $\kappa \mathrm{B}$ and $\mathrm{p} 53$ (Figure 3D, and results not shown) and the chromatin immunoprecipitation analysis for in situ binding with antibodies against ETS-2, Elf-1, ETS-1 and p50 (of NF- $\mathrm{kB}$ ), respectively (Figure 6).

The ETS gene family encompasses a group of DNAbinding proteins characterized by a conserved DNA-binding "ETS" domain $[19,20]$. This family is involved in cellular growth and differentiation, as well as in various disease states, including human cancers [21, 22]. While some members of the ETS family are expressed ubiquitously, others exhibit cell-type-specific expression. For instance, both ETS-1 [5] and Elf-1 [23] genes show restricted expression in the lymphoid lineages. Disruption of the ETS-1 gene in mouse causes abnormal maturation of the natural killer cell lineage [24]. Binding sites for Elf-1 have been identified in the promoters of several important lymphoid-specific genes such as $I L-3$ [23] and GM-CSF [23]. ETS-2 has a distinct tissue-specific expression pattern $[25,26]$. Deficiency of the ETS-2 gene leads to day E8.5 embryonic lethality, with defects in extraembryonic tissue gene expression and function and the failure of ectoplacental cone proliferation [27]. We found that all of these three 
ETS transcription factors are expressed abundantly in the two nonhematopoietic cell lines: SMMC7721 (from a liver cancer) and C33A (from a cervical cancer) (Figure 6A, 6B and 6D). The aberrant expression of these three ETS genes seems common in human cancers from the normal cell lineage pattern.

ETS domain-mediated binding has been specified to a large number of sequences with the core nucleotide sequence GGAA/T [20, 22], but the specificity of the binding of each ETS transcription factors varies significantly with the sequence variation flanking the core sequence. We started EMSA experiments with two different consensus sequences: ETS-1 (PEA3) [28] and ETS-2 (Elf-1) [29] and found that only the ETS-2 (Elf-1) consensus sequence effectively competed for binding of the SMMC7721 nuclear proteins to the +1 to +40 sequence (WT) (Figure $3 \mathrm{~A}$ ). The ETS-2 (Elf-1) consensus sequence CCGGAAGT was matched perfectly, while the ETS-1 (PEA3) consensus sequence GCAGGAAGT differed by one or two nucleotides at each ETS site in the +1 to +40 region (the underlined residues are unmatched, Figure 3A). Furthermore, the supershifts showed that ETS-2 and/or Elf-1, but not ETS1 , were directly bound to the +1 to +40 sequence (Figure $3 \mathrm{E}$ and the unpublished observations). As these three ETS proteins were expressed at similar levels in the two HCCS1expressing tumor cell lines (SMMC7721 and C33A; Figure $6 \mathrm{~A}$ and $6 \mathrm{~B}$ ), the absence of ETS- 1 binding to the +1 to +40 sequence was not caused by a lack of ETS-1 protein in the cells. This was also consistent with the results from the ChIP analyses of the cross-linked SMMC7721 chromatin (Figure 6B), showing that both ETS-2 and Elf-1, but not ETS-1, indeed bound in situ to the ETS consensus sites at +4 to +20 and +23 to +39 (both within the +1 to +40 region). As ETS-2 differs from ETS-1 by a single amino acid in the DNA-binding domain, the evidence for the opposite behavior and roles of these two proteins (Figures 3A, 3E, $5 \mathrm{C}, 5 \mathrm{G}$ and $6 \mathrm{~A}, 6 \mathrm{~B}$ and $6 \mathrm{E}$ ) requires a less straightforward mechanistic explanation. Both differential post-translational modifications and protein-protein interactions should be to be considered.

Protein-protein interactions regulate the DNA binding, subcellular localization, target-gene selection and transcription activity of ETS proteins [30], the partners of which include AP-1, NF- $\mathrm{BB}$ and Pax family members. In this respect, addition of either p53 or the p50 and p65 components of NF- $\mathrm{kB}$ did not alter ETS-2's effects on the promoter activity of ES and its mutants $(\mathrm{m} 5, \mathrm{~m} 6$ and $\mathrm{m} 56$ : in which the ETS sites within the +1 to +40 region were differentially affected, the unpublished results), implying that protein-protein interactions between ETS-2 and NF$\kappa \mathrm{B}$ or p53 may not have an apparent role in the control of HCCS1 transcription.
Neither p53-nor $N F-\kappa B$-mediated signaling pathways play a significant role in the transcription regulation of the HCCS1 gene in both stressed and unstressed cells

Signaling pathways activated by growth factors or cellular stresses, such as those involving MAP kinases, Erk1 and 2, p38 and JNK, the PI3 kinases and $\mathrm{Ca}^{2+}$-specific signals, have been shown to converge on the ETS factors, so that ETS activity, protein partnerships and the specification of downstream target genes are finely regulated [31]. The possible involvement of either $\mathrm{p} 53$ or NF- $\mathrm{kB}$ pathways in the control of HCCS1 transcription was suggested by their (bioinformatically predicted) consensuses in the +1 to +40 region of the HCCS1 promoter (Figure 3A). Regulation of transcription is a major molecular mechanism underlying the tumor-suppressing effects of the $\mathrm{p} 53$ protein [32]. Genes activated by 553 include those that mediate apoptosis, DNA repair, cell cycle arrest and the control of angiogenesis, whereas antiapoptotic and pro-proliferation genes are suppressed by $\mathrm{p} 53$ [33]. On the other hand, the NF- $\kappa$ B pathway plays a paramount role in both immunity and inflammation. It has a number of pro-oncogenic activities and is overactivated in many cancerous conditions [34-37]. However, both pathways are dormant under the physiological conditions and therefore inactive in the routine cell culture. Therefore, the negative finding in the in vitro DNA-protein interaction studies (Figure 3A and the unpublished data) in the unstressed SMMC7721 cells remains inconclusive. To this end, we activated p53 with Dox or the NF-kB pathway with TNF- $\alpha$, followed by the assessment of sequence-specific binding in vitro (Figure 5B for NF- $\mathrm{KB}$ and Figure 5F for $\mathrm{p} 53$ ) and the promoter activity in cells (Figure 5A for NF$\kappa \mathrm{B}$, and Figure 5E for $\mathrm{p} 53$ ). As shown in Figure 5A and $5 \mathrm{C}$ for NF- $\mathrm{KB}$ pathways, and Figure $5 \mathrm{E}$ and $5 \mathrm{G}$ for $\mathrm{p} 53$ pathways, the evidence in the stressed SMMC7721 cells argues strongly against the possible significant participation of NF- $\kappa \mathrm{B}$ and/or p53-mediated signaling pathways in the control of HCCS1 transcription.

Our attempts to delineate the molecular details of the mechanisms underlying transcriptional regulation of the HCCS1 gene, a putative HCC suppressor, have yielded a number of important mechanistic insights. Future efforts will be directed at molecular characterization of the protein-protein interactions of ETS-2 and/or Elf-1, as well as upstream signals and pathways, in the context of HCCSI transcription.

\section{Acknowledgments}

Thanks are due to Y Shi and W Heniig for their comments on this manuscript, as well as H Ji and N Rice for their kind provision of constructs. This work was supported by grants to Jing De Zhu from the Shanghai Science Foun- 
dation (04DZ14006 and 05DZ19318), the National Science Foundation (30450001, 30570850 and 10574134) and the National Research Program for Basic Research of China (2004CB518804 and 2002CB713700).

\section{References}

1 Block TM, Mehta AS, Fimmel CJ, Jordan R. Molecular viral oncology of hepatocellular carcinoma. Oncogene 2003; 22:50935107.

2 Coleman WB. Mechanisms of human hepatocarcinogenesis. Curr Mol Med 2003; 3:573-588.

3 Zhao X, Li J, He Y, et al. A novel growth suppressor gene on chromosome $17 \mathrm{p} 13.3$ with a high frequency of mutation in human hepatocellular carcinoma. Cancer Res 2001; 61:73837387.

4 Wan D, Gong Y, Qin W, et al. Large-scale cDNA transfection screening for genes related to cancer development and progression. Proc Natl Acad Sci USA 2004; 101:15724-15729.

5 Xiao W, Park CK, Park JY, et al. Genetic alterations of the HCCS1 gene in Korean hepatocellular carcinoma. Apmis 2003; 111:465-473.

6 Boeger H, Bushnell DA, Davis R, et al. Structural basis of eukaryotic gene transcription. FEBS Lett 2005; 579:899-903.

7 Ercan S, Carrozza MJ, Workman JL. Global nucleosome distribution and the regulation of transcription in yeast. Genome Biol 2004; 5:243.

8 Neely KE, Workman JL. The complexity of chromatin remodeling and its links to cancer. Biochim Biophys Acta 2002; 1603:1929.

9 Christensen RA, Fujikawa K, Madore R, Oettgen P, Varticovski L. NERF2, a member of the Ets family of transcription factors, is increased in response to hypoxia and angiopoietin-1: a potential mechanism for Tie2 regulation during hypoxia. J Cell Biochem 2002; 85:505-515.

10 Hoffman WH, Biade S, Zilfou JT, Chen J, Murphy M. Transcriptional repression of the anti-apoptotic survivin gene by wild type p53. J Biol Chem 2002; 277:3247-3257.

11 Zhu J, Gao B, Zhao J, Balmain A. Targeting gene expression to tumor cells with loss of wild-type p53 function. Cancer Gene Ther 2000; 7:4-12.

$12 \mathrm{Xu}$ J, Zhu J, Ni M, Wan D, Gu JR. The ATF/CREB site is the key element for transcription of the human RNA methyltransferase like 1(RNMTL1) gene, a newly discovered 17 p13.3 gene. Cell Res 2002; 12:177-197.

13 Kielbasa SM, Gonze D, Herzel H. Measuring similarities between transcription factor binding sites. BMC Bioinformatics 2005; 6:237.

14 Kastan MB, Zhan Q, el-Deiry WS, et al. A mammalian cell cycle checkpoint pathway utilizing p53 and GADD45 is defective in ataxia-telangiectasia. Cell 1992; 71:587-597.

15 Harris SL, Levine AJ. The p53 pathway: positive and negative feedback loops. Oncogene 2005; 24:2899-2908.

16 Cai L, Zhu JD. The tumor-selective over-expression of the human Hsp70 gene is attributed to the aberrant controls at both initiation and elongation levels of transcription. Cell Res 2003;
13:93-109.

17 Modugno M, Tagliabue E, Ardini E, et al. p53-dependent downregulation of metastasis-associated laminin receptor. Oncogene 2002; 21:7478-7487.

18 Conibear E, Stevens TH. Vps52p, Vps53p, and Vps54p form a novel multisubunit complex required for protein sorting at the yeast late Golgi. Mol Biol Cell 2000; 11:305-323.

19 Oikawa T, Yamada T. Molecular biology of the Ets family of transcription factors. Gene 2003; 303:11-34.

20 Sharrocks AD. The ETS-domain transcription factor family. Nat Rev Mol Cell Biol 2001; 2:827-837.

21 Gilliland DG. The diverse role of the ETS family of transcription factors in cancer. Clin Cancer Res 2001; 7:451-453.

22 Seth A, Watson DK. ETS transcription factors and their emerging roles in human cancer. Eur J Cancer 2005; 41:2462-2478.

23 John S, Marais R, Child R, Light Y, Leonard WJ. Importance of low affinity Elf-1 sites in the regulation of lymphoid-specific inducible gene expression. J Exp Med 1996; 183:743-750.

24 Barton K, Muthusamy N, Fischer C, et al. The Ets-1 transcription factor is required for the development of natural killer cells in mice. Immunity 1998; 9:555-563.

25 Baker KM, Wei G, Schaffner AE, Ostrowski MC. Ets-2 and components of mammalian SWI/SNF form a repressor complex that negatively regulates the BRCA1 promoter. J Biol Chem 2003; 278:17876-17884.

26 Kang AD, Park G, Kim YH, Oh IH. Differential modulation of Myb family genes by Ets-2. Oncogene 2004; 23:4177-4181.

27 Yamamoto H, Flannery ML, Kupriyanov S, et al. Defective trophoblast function in mice with a targeted mutation of Ets2. Genes Dev 1998; 12:1315-1326.

28 Fisher RJ, Koizumi S, Kondoh A, et al. Human ETS1 oncoprotein. Purification, isoforms, -SH modification, and DNA sequence-specific binding. J Biol Chem 1992; 267:17957-17965.

29 Sapru MK, Florance SK, Kirk C, Goldman D. Identification of a neuregulin and protein-tyrosine phosphatase response element in the nicotinic acetylcholine receptor epsilon subunit gene: regulatory role of an Rts transcription factor. Proc Natl Acad Sci USA 1998; 95:1289-1294.

30 Li R, Pei H, Watson DK. Regulation of Ets function by proteinprotein interactions. Oncogene 2000; 19:6514-6523.

31 Yordy JS, Muise-Helmericks RC. Signal transduction and the Ets family of transcription factors. Oncogene 2000; 19:6503-6513.

$32 \mathrm{Lu} \mathrm{X}$. p53: a heavily dictated dictator of life and death. Curr Opin Genet Dev 2005; 15:27-33.

33 Vousden KH, Lu X. Live or let die: the cell's response to p53. Nat Rev Cancer 2002; 2:594-604.

34 Aggarwal BB. Nuclear factor-kappaB: the enemy within. Cancer Cell 2004; 6:203-208.

35 Balkwill F, Coussens LM. Cancer: an inflammatory link. Nature 2004; 431:405-406.

36 Clevers H. At the crossroads of inflammation and cancer. Cell 2004; 118:671-674.

37 Luo JL, Maeda S, Hsu LC, Yagita H, Karin M. Inhibition of NF-kappaB in cancer cells converts inflammation-induced tumor growth mediated by TNFalpha to TRAIL-mediated tumor regression. Cancer Cell 2004; 6:297-305. 